\title{
Aftershock Sequences Modeled with 3-D Stress Heterogeneity and Rate-State Seismicity Equations: Implications for Crustal Stress Estimation
}

\author{
Deborah Elaine Smith ${ }^{1}$ and James H. Dieterich ${ }^{1}$
}

\begin{abstract}
In this paper, we present a model for studying aftershock sequences that integrates Coulomb static stress change analysis, seismicity equations based on rate-state friction nucleation of earthquakes, slip of geometrically complex faults, and fractal-like, spatially heterogeneous models of crustal stress. In addition to modeling instantaneous aftershock seismicity rate patterns with initial clustering on the Coulomb stress increase areas and an approximately $1 / \mathrm{t}$ diffusion back to the pre-mainshock background seismicity, the simulations capture previously unmodeled effects. These include production of a significant number of aftershocks in the traditional Coulomb stress shadow zones and temporal changes in aftershock focal mechanism statistics. The occurrence of aftershock stress shadow zones arises from two sources. The first source is spatially heterogeneous initial crustal stress, and the second is slip on geometrically rough faults, which produces localized positive Coulomb stress changes within the traditional stress shadow zones. Temporal changes in simulated aftershock focal mechanisms result in inferred stress rotations that greatly exceed the true stress rotations due to the main shock, even for a moderately strong crust (mean stress $50 \mathrm{MPa}$ ) when stress is spatially heterogeneous. This arises from biased sampling of the crustal stress by the synthetic aftershocks due to the non-linear dependence of seismicity rates on stress changes. The model indicates that one cannot use focal mechanism inversion rotations to conclusively demonstrate low crustal strength $(\leq 10 \mathrm{MPa})$; therefore, studies of crustal strength following a stress perturbation may significantly underestimate the mean crustal stress state for regions with spatially heterogeneous stress.
\end{abstract}

Key words: Stress heterogeneity, rate-state, fractal, aftershock, Coulomb stress, crustal strength.

\section{Introduction}

We investigate aftershock sequences using simulations that combine several features, namely: (1) Coulomb static stress change analysis, (2) seismicity

1 University of California, Riverside, CA 92521, USA. E-mail: desmith144@gmail.com equations based on rate-state friction nucleation of earthquakes from Dieterich (1994) and Dieterich et al. (2003), (3) slip on geometrically complex faults as in Dieterich and SMith (2009), and (4) spatially heterogeneous fault planes/slip directions based on a model of fractal-like spatially variable initial stress from Sмith (2006) and Sмith and Heaton (2010). Our goal is to investigate previously unmodeled effects of system heterogeneities on aftershock sequences. The resulting model provides a unified means to simulate the statistical characteristics of aftershock focal mechanisms, including inferred stress rotations, and to provide insights on the persistent low-level occurrence of aftershocks in the Coulomb stress "shadow zones" (regions where Coulomb stress decreases).

Coulomb static stress change failure analysis has been extensively used to study the spatial distribution of aftershocks for moderate to large earthquakes (Deng and Sykes, 1997a, b; HaRdebeck et al., 1998; HARris and Simpson, 1996; Harris et al., 1995; KING et al., 1994; OpPENHEIMER et al., 1988; REASENBERG and Simpson, 1992; Stein et al., 1994). In general, the change of Coulomb stress due to fault slip in a mainshock works well in explaining aftershock patterns, but not perfectly. Depending upon the individual mainshock, the performance of Coulomb static stress triggering models can range from 50\% correlation, which is no better than random noise, to a 95\% correlation, and with many reports around the 85\% correlation level (Deng and SyKes, 1997a, b; HARDEBECK et al., 1998).

Rate-state friction, as well as other mechanisms (such as viscoelastic relaxation), has been used to explain temporal changes in seismicity rate and 
migration of events (Dieterich, 1994; Pollitz and SACKS, 2002; SteIn, 1999; STein et al., 1997; TodA and Stein, 2003; Toda et al., 1998). Our study employs the earthquake rate formulation of DIETERICH (1994) and Dieterich et al. (2003), which is based on time- and stress-dependent earthquake nucleation on faults with rate- and state-dependent friction. The formulation explains temporal features of aftershocks, such as the Omori law decay in aftershock seismicity rate, as consequences of Coulomb stress changes; it provides a natural framework for investigation of the effects of heterogeneities on aftershock processes.

Natural systems, which are inherently complex, must be heterogeneous at some level. In our model, stresses drive the aftershock process and determine the orientations at which faults fail. Stress heterogeneity can arise through a variety of mechanisms, including propagation of fault slip through geometric complexities, rupture dynamics that creates highly non-uniform slip, and inhomogeneous elastic structure. A variety of observations indicate that stress and slip are spatially heterogeneous and possibly fractal in nature (ANDREws, 1980, 1981; BEN-ZION and Sammis, 2003; Herrero and Bernard, 1994; Lavallee and Archuleta, 2003; Mai and Beroza, 2002; Manighetti et al., 2001, 2005). McGill and Rubin (1999) in particular, observed extreme changes in slip over short distances for the Landers earthquake. Borehole studies of stress orientation provide additional evidence that stress can be quite heterogeneous (BARTON and Zoback, 1994; Wilde and Stock, 1997). Studies also indicate that stress heterogeneity is wavelength dependent; namely, there is a greater stress uniformity at short scales than at long scales.

Faults in nature are not geometrically planar surfaces-faults have irregularities at all wavelengths and can be depicted approximately as random fractal topographies (Power and Tuluis, 1991; Scholz and Aviles, 1986). Geometric interactions from slip of faults with random fractal roughness generate complex, high amplitude stress patterns close to and along the fault (DIETERICH and Smith, 2009). While these stress concentrations die off with distance, they may be the primary reason for the characteristic high density of aftershocks close to the fault in the traditional stress shadow zone. An intriguing observation derives from ZoBACK and BEROZA (1993), who reported scattered focal mechanism solutions for Loma Prieta aftershocks, including left-lateral orientations on fault planes parallel to the San Andreas. A plausible explanation is that the stress was highly heterogeneous after the earthquake with short wavelength pockets of high stress in random directions.

Helmstetter and SHaw (2006) modeled the effect of a heterogeneous shear stress change on a plane for aftershock rates in light of rate- and state-dependent friction. Using two different, heterogeneous stress formulations, they produced Omori law-like decay of aftershocks and found that stress shadows are difficult to see. In another study (Helmstetter and SHAw, 2009), they used a simple slider block system to examine afterslip and aftershocks for a fault obeying rate-state friction and found that stress heterogeneity, as opposed to frictional heterogeneity, could explain a variety of post-seismic phenomena.

In addition to heterogeneous stress changes at the time of a mainshock, we assume the initial stress is heterogeneous and produces heterogeneous fault plane orientations on which aftershocks occur. To generate a heterogeneous population of fault orientations (and slip vectors) for aftershocks, we use a representation of a heterogeneous stress field based on Smith (2006) and Smith and Heaton (2010). The spatially varying models of the full stress tensor allowed Smith and Heaton to estimate best fitting stochastic parameters for Southern California focal mechanism data. Also, the model indicates earthquake failures are preferred for faults that are optimally oriented with respect to stressing rate; hence, stress inversions of focal mechanism data may be biased as well.

The sample bias effect may bear directly on the use of stress inversions of aftershock focal mechanisms to determine crustal stress properties, such as crustal stress heterogeneity and crustal strength. An implicit assumption in these studies is that the Earth is a good random sampler of its stress state when generating earthquakes; therefore, changes in the stress inversion mean misfit angle, $\beta$, and rotations of the inferred maximum horizontal compressive stress, $\sigma_{H}$, from stress inversion of aftershock sequences are assumed to represent true 
changes in stress (HARDEBECK and HauksSON, 2001; Hauksson, 1994; Provost and Houston, 2003; RATchKovsKi, 2003; WoEssner, 2005). These studies used inferred $\sigma_{H}$ rotations to constrain average crustal stress and often estimate $\leq 10 \mathrm{MPa}$. However, if seismicity is a biased sampler of conditions in the Earth, the inferred $\sigma_{H}$ rotations could be larger than the "true" rotation of the total stress field, and the actual crustal stress could be much larger than $10 \mathrm{MPa}$. This may explain the discrepancy between estimates of crustal stress based on stress rotation and estimates of $\geq 80 \mathrm{MPa}$ from independent measures of crustal strength, such as borehole breakouts (HickMAN and ZOBACK, 2004; TOWNEND and ZовACK, 2000, 2004; ZовACK and Townend, 2001; Zоваск et al., 1993). Previous studies have proposed other potential sources of error in stress inversions (ARNOLD and TOWNEND, 2007; Lund and Townend, 2007; TownEND, 2006; Townend and Zoback, 2001; Walsh et al., 2008).

\section{Rate- and State-dependent Friction}

As with previous studies (STEIN, 1999; STEIN et al., 1997; Toda and Stein, 2003; Toda et al., 1998), we use the seismicity rate formulation of Dieterich (1994) to model aftershock rates. This formulation is based on rate- and state-dependent friction constitutive representation of laboratory observations, which can be written as

$$
\tau=\sigma_{n}\left[\mu_{0}+a \ln \left(\frac{\dot{\delta}}{\dot{\delta} *}\right)+b \ln \left(\frac{\theta}{\theta *}\right)\right],
$$

where $\tau$ is shear stress, $\sigma_{n}$ is normal stress, $\dot{\delta}$ is slip speed, and $\theta$ is a state variable that depends on sliding history and normal stress history. $a, b$, and $\mu_{0}$ are coefficients determined by experiment, and $\dot{\delta} *$ and $\theta^{*}$ are normalizing constants.

This earthquake rate formulation employs solutions for earthquake nucleation on faults with ratestate friction (DIETERICH, 1992), and it provides a way to represent seismicity. Earthquake rate is both timeand stress-dependent and can be written in terms of Coulomb stress (DieTERICH et al., 2003)

$$
R=\frac{r}{\gamma \dot{S}_{r}}
$$

and

$$
d \gamma=\frac{1}{a \sigma_{n}}[d t-\gamma d S],
$$

where $R$ is earthquake rate in some magnitude interval, $S=\tau-\mu \sigma_{n}$ is a Coulomb stress, $\dot{S}_{r}$ and $r$ are reference values of the stressing rate and steady-state earthquake rate, respectively, and $\gamma$ is a state variable that evolves with time and stressing history. The equations also give the characteristic Omori aftershock decay law and predict that aftershock duration is proportional to mainshock recurrence time. Also see Dieterich (2007) for a review and discussion of the rate-state formulation and applications to seismicity modeling.

\section{A Model of 3-D Spatially Varying Stress Heterogeneity}

To generate a system of temporally stationary heterogeneous fault planes/slip directions, we use the following model of spatially varying stress heterogeneity in 3-D (Smith, 2006; Smith and Heaton, 2010). Seismicity rates will be determined on these fault planes/slip directions using rate-state friction. SмIтH (2006) is available online at http://etd.caltech. edu/etd/available/etd-05252006-191203/.

Smith (2006) and Smith and Heaton (2010) defined the initial stress as,

$$
\boldsymbol{\sigma}^{0}(\mathbf{x})=\boldsymbol{\sigma}^{B}+\boldsymbol{\sigma}^{H}(\mathbf{x}),
$$

where $\boldsymbol{\sigma}^{B}$ is a spatially uniform background stress that is approximately equal to the spatial average of $\boldsymbol{\sigma}^{0}(\mathbf{x})$ for the entire grid. $\boldsymbol{\sigma}^{H}(\mathbf{x})$ is the full 3-D heterogeneous stress term with little to no spatial mean; i.e., $\boldsymbol{\sigma}^{H}(\mathbf{x}) \approx \boldsymbol{\sigma}^{0}(\mathbf{x})-\overline{\boldsymbol{\sigma}}^{0}(\mathbf{x})$. This term, $\boldsymbol{\sigma}^{H}(\mathbf{x})$, is created by filtering Gaussian noise in 3-D and then added to $\boldsymbol{\sigma}^{B}$ to create $\boldsymbol{\sigma}^{0}(\mathbf{x})$. In generating the Gaussian noise, Smith and Heaton (2010) prescribed the off-diagonal elements to have an expected mean/standard deviation of $(0, \sigma)$ and the diagonal elements to have an expected mean/standard deviation of $(0, \sqrt{2} \sigma)$. Then a 3-D filter is applied so the spatial amplitude 
spectrum of any component of stress along any line bisecting the model is described by a power law,

$$
\tilde{\boldsymbol{\sigma}}^{H}\left(k_{r}\right) \sim k_{r}^{-\alpha},
$$

where $k_{r}$ is wave number. The parameter, $\alpha$, is a measure of the spatial correlation in the filtered heterogeneous stress term, $\boldsymbol{\sigma}^{H}(\mathbf{x})$. If $\alpha=0.0$, there is no filtering, and as $\alpha$ increases, the spatial heterogeneity becomes increasingly smoother and correlated spatially.

Note, the only difference between the stress model of SMith (2006) and the stress model of SMITH and Heaton (2010) arises from the methodology used to create $\boldsymbol{\sigma}^{H}(\mathbf{x})$. Instead of starting with normally distributed tensor components as described above, Sмітн (2006) started with normally distributed principal stresses with a mean of zero and uniformly distributed random orientations based on quaternion mathematics. Wave number filtering is then applied to the three principal stresses and to the stress tensor orientation, represented by three angles $(\omega,[\theta, \phi])$, where $\omega$ is a total rotation angle about a rotation axis, $[\theta, \phi]$. Both methodologies produce similar seismicity statistics and biasing toward the stressing rate; however, for mathematical simplicity, we use the methodology of Sмith and Heaton (2010) for this paper in creating $\boldsymbol{\sigma}^{H}(\mathbf{x})$.

Once $\boldsymbol{\sigma}^{H}(\mathbf{x})$ has been filtered, its overall amplitude is set relative to the spatially uniform, $\boldsymbol{\sigma}^{B}$. This relative heterogeneity amplitude is described, using a second statistical parameter, $H R$ (Heterogeneity Ratio), based on the deviatoric stresses, where

$$
H R=\frac{\sqrt{\overline{\left[\boldsymbol{\sigma}^{\prime H}(\mathbf{x}): \boldsymbol{\sigma}^{\prime H}(\mathbf{x})\right]}}}{\sqrt{\boldsymbol{\sigma}^{\prime B}: \boldsymbol{\sigma}^{\prime B}}} .
$$

Note that

$$
\begin{aligned}
\boldsymbol{\sigma}^{\prime B}: \boldsymbol{\sigma}^{\prime B}= & \left(\sigma_{11}^{\prime B}\right)^{2}+\left(\sigma_{22}^{\prime B}\right)^{2}+\left(\sigma_{33}^{\prime B}\right)^{2}+2\left(\sigma_{12}^{\prime B}\right)^{2} \\
& +2\left(\sigma_{23}^{\prime B}\right)^{2}+2\left(\sigma_{13}^{\prime B}\right)^{2}
\end{aligned}
$$

and

$$
\overline{\left[\boldsymbol{\sigma}^{\prime H}(\mathbf{x}): \boldsymbol{\sigma}^{\prime H}(\mathbf{x})\right]}=\frac{1}{N} \sum_{i=1}^{N} \boldsymbol{\sigma}^{\prime H}\left(x_{i}\right): \boldsymbol{\sigma}^{\prime H}\left(x_{i}\right) .
$$

$H R$ is analogous to a coefficient of correlation since it computes a quantity that is like the standard deviation of $\boldsymbol{\sigma}^{\prime 0}(\mathbf{x})$ divided by its mean.
Smith and Heaton (2010) and Smith (2006) compared statistics of synthetic focal mechanisms from their 3-D spatially heterogeneous stress to the statistics of real focal mechanisms from HARDEBECK (2006) and Hardebeck's SCEC catalog (HARDEBECK and SHEARER, 2003) for Southern California to constrain $\alpha$ and HR. To create their synthetic focal mechanism catalogs for comparison with real focal mechanism data, Smith and Heaton added a stressing rate, $\dot{\boldsymbol{\sigma}}^{T}$, from far-field plate tectonics and used a plastic failure criterion to determine when points fail within the simulation space. They varied the two statistical parameters, $\alpha$ and $H R$, to create suites of synthetic focal mechanisms' catalogs with different stochastic properties. SMith and Heaton (2010) undertook a five-parameter grid search $\left(\alpha, H R, \varepsilon_{F M}\right.$, $\left.\varepsilon_{\text {hypo }}, L\right)$, which included the two statistical parameters, $\alpha$ and $H R$, two simulated measurement error parameters, focal mechanism angular uncertainty $\left(\varepsilon_{F M}\right)$ and location error $\left(\varepsilon_{\text {hypo }}\right)$, and the outer-scale, $L$, to find which set of parameters best reproduces real focal mechanism statistics. Specifically, they calculated the average angular difference between pairs of focal mechanisms as a function of distance for each set of $\left(\alpha, H R, \varepsilon_{F M}, \varepsilon_{\text {hypo }}, L\right)$ and compared their results to HARDEBECK (2006), with a best fit in the range of $(\alpha=0.7-0.8, H R=2.25-2.5)$ (Smith and Heaton, 2010). Sмiтн (2006), using a less rigorous inversion technique and the slightly different stress model, found comparable results. Smith and Heaton also found their inverted parameters to be consistent with mean misfit angle, $\beta$, statistics. Applying the stress inversion program "slick" (MichAEL, 1984, 1987) to their synthetic focal mechanisms for $(\alpha=0.8, H R=$ 2.375) and to Hardebeck's A and B quality focal mechanism data for Southern California (HARDEBECK and SHEARER, 2003), they found the mean misfit angle statistics between their simulated data and Southern California data to be compatible.

Figure 1 shows a 1-D cross section of filtered synthetic stress using $(\alpha=0.7, H R=2.5)$, which are the heterogeneous stress parameters for the models in this paper. In Fig. 1, all the components of $\boldsymbol{\sigma}^{B}$ equal zero except $\sigma_{12}^{B} \neq 0$. A random $\boldsymbol{\sigma}^{H}(x)$ is filtered with $\alpha=0.7$, then added to $\boldsymbol{\sigma}^{B}$, where the relative amplitudes are specified by $H R=2.5$ to create $\boldsymbol{\sigma}^{0}(x)$. $\boldsymbol{\sigma}^{0}(x)$ is scaled so that $200 \mathrm{MPa} \geq \sigma_{12}^{0}(x) \geq$ 


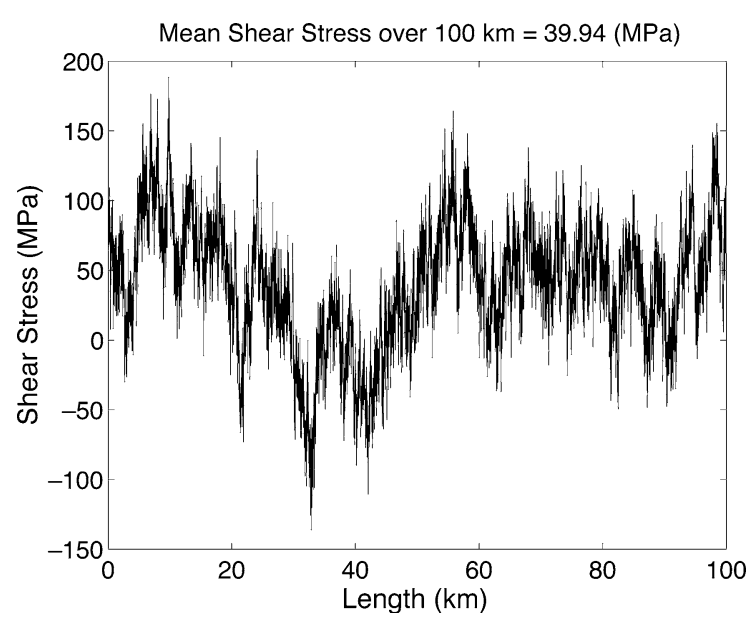

Figure 1

This is one realization of heterogeneous shear stress with parameters $(\alpha=0.7, H R=2.5)$ and max shear stress about $200 \mathrm{MPa}$. Wave number filtering with $\alpha=0.7$ produces this model of stress with greater spatial correlation at short distances than at long distances. Consequently, if one averages over the entire length of $100 \mathrm{~km}$, the mean shear stress is approximately $40 \mathrm{MPa}$; however, if one were to average over an asperity, considerably higher mean shear stresses can be obtained (Elbanna and Heaton, 2010; Smith, 2006; Smith and Heaton, 2010)

$-200 \mathrm{MPa}$, and then $\sigma_{12}^{0}(x)$ is plotted. This model of stress heterogeneity produces great spatial variability in shear stress over the scale of $50-100 \mathrm{~km}$; however, over the scale of $1-5 \mathrm{~km}$, the stress is relatively uniform. This arises from the wave number filtering of $\boldsymbol{\sigma}^{H}(x)$, with $\alpha=0.7$.

\section{Methodology}

In creating our synthetic aftershock sequences, we utilize: (1) the above 3-D heterogeneous stress model (Smith, 2006; Smith and Heaton, 2010) to define our failure planes/slip directions, (2) a spatially uniform far-field stressing rate and a spatially variable stress change from slip on a geometrically complex fault to create our stressing history, (3) rate-state seismicity equations (DIETERICH, 1994; DieTERICH et al., 2003) to evolve the seismicity rates on these failure planes/slip directions, given the stressing history, and (4) a random number generator to produce synthetic failures, assuming the earthquakes are a Poissonian process with spatially and temporally varying seismicity rates.
We are not aiming to delineate precise aftershock behavior, nor do we claim to know stress heterogeneity exactly. Instead, our goal is to demonstrate a general effect on aftershock sequences when preexisting stress heterogeneity is included; hence, the parameters $(\alpha=0.7, H R=2.5)$ are a reasonable place to start in creating the initial stress, $\sigma^{0}(\mathbf{x})$. For all simulations, a deviatoric amplitude of $\left(\sigma_{1}-\sigma_{3}\right) / 2=$ $50 \mathrm{MPa}$ is used for $\boldsymbol{\sigma}^{B}$, and the exact eigenvector orientations/relative eigenvalue sizes are selected a priori at the beginning of the simulation.

Then the outliers of $\boldsymbol{\sigma}^{0}(\mathbf{x})$ are clipped so that the maximum deviatoric amplitudes are in the range of granitic rock yield strength (Scholz, 2002). The offdiagonal components are given a min/max value of $\pm 200 \mathrm{MPa}$, and the diagonal components are given a $\mathrm{min} / \mathrm{max}$ value of $\pm 200 \sqrt{2} \mathrm{MPa}$ since the original heterogeneous stress, $\boldsymbol{\sigma}^{H}(\mathbf{x})$, is generated using a normal distribution with standard deviation $\sigma$ for off-diagonal components and $\sqrt{2} \sigma$ for diagonal components.

A Coulomb failure criterion is then applied to the initial heterogeneous stress field, $\boldsymbol{\sigma}^{0}(\mathbf{x})$, to create two possible failure planes/slip directions at each point in the 3-D grid. The two possible failure planes are planes rotated $\pm \theta$ from the most compressive principal stress axis for $\boldsymbol{\sigma}^{0}(\mathbf{x})$, where $\theta=\frac{\pi}{4}-\frac{\tan ^{-1}(\mu)}{2}$, where $\mu=0.4$. A coefficient of friction slightly less than 0.6 is used partially because low coefficients of friction tend to best fit the Coulomb static stress analysis (REASENBERg and Simpson, 1992). Slip directions on the failure planes lie in the $\sigma_{1}, \sigma_{3}$ plane to produce optimal Coulomb failures. We label the two sets of failure planes/slip directions by the normal vectors to the planes and by the slip vectors, $\left(\mathbf{n}^{R L}, \mathbf{l}^{R L}\right)$ for right-lateral mechanisms and $\left(\mathbf{n}^{L L}, \mathbf{l}^{L L}\right)$ for left-lateral mechanisms.

Even though the total stress will change with time, any changes are treated as perturbations to the initial stress, $\boldsymbol{\sigma}^{0}(\mathbf{x})$; hence, $\left(\mathbf{n}^{R L}, \mathbf{l}^{R L}\right)$ and $\left(\mathbf{n}^{L L}, \mathbf{l}^{L L}\right)$ are stationary in time. The equation for total stress (SMITH, 2006; Smith and Heaton, 2010) is

$$
\boldsymbol{\sigma}(\mathbf{x}, t)=\boldsymbol{\sigma}^{0}(\mathbf{x})+\dot{\boldsymbol{\sigma}}^{T}\left(t-t_{0}\right)+\Delta \boldsymbol{\sigma}^{F}(\mathbf{x}),
$$

where $\dot{\boldsymbol{\sigma}}^{T}$ is the far-field stressing rate from platetectonics, $t_{0}$ is the time since the mainshock, and $\Delta \boldsymbol{\sigma}^{F}(\mathbf{x})$ is the static stress change from the mainshock. 
$\dot{\boldsymbol{\sigma}}^{T}$ and $\Delta \boldsymbol{\sigma}^{F}(\mathbf{x})$ are treated as perturbations since their magnitudes are much smaller than the spatially heterogeneous initial stress, $\boldsymbol{\sigma}^{0}(\mathbf{x})$, in our simulations.

We now apply a stressing history defined by the background tectonic stressing rate, $\dot{\boldsymbol{\sigma}}^{T}$, and the 3-D static stress change, $\Delta \boldsymbol{\sigma}^{F}(\mathbf{x})$, calculated from Okada's equations for slip on a dislocation (ОкADA, 1992), onto this population of failure planes/slip directions $\left(\mathbf{n}^{R L}, \mathbf{l}^{R L}\right)$ and $\left(\mathbf{n}^{L L}, \mathbf{l}^{L L}\right)$. In turn, this stressing history resolved onto $\left(\mathbf{n}^{R L}, \mathbf{l}^{R L}\right)$ and $\left(\mathbf{n}^{L L}, \mathbf{l}^{L L}\right)$ can be used as input for the rate-state earthquake rate equations from DieTERICH (1994) and Dieterich et al. (2003) to update the seismicity rates at every point in the grid throughout the aftershock period. When we use Eqs. 2 and 3 in this paper, we set $a \sigma_{n}=0.2 \mathrm{MPa}$.

To implement Eqs. 2 and 3 to evolve the seismicity rates on the pre-existing planes/slip directions, it is necessary to first set the initial value $\gamma_{0}$ for each fault surface/slip direction in the model. We assume a steady-state condition wherein seismicity rate is constant. This requires that $\gamma_{0}=\frac{1}{\dot{S}_{r}}$, where $\dot{S}_{r}=\dot{\tau}^{T}-$ $\mu \dot{\sigma}_{n}^{T}$ is the resolved Coulomb stress rate for tectonic loading on the failure plane in the specified slip direction. $\dot{\boldsymbol{\sigma}}^{T}$ is resolved into both sets of failure orientations, $\left(\mathbf{n}^{R L}, \mathbf{l}^{R L}\right)$ and $\left(\mathbf{n}^{L L}, \mathbf{l}^{L L}\right)$, because when $\mu=0.4$, the two planes at each point form an angle $<90^{\circ}$ and will not have the same resolved Coulomb stress rates, $\dot{S}_{r}$. Generally, $\dot{S}_{r}$ will have different values at each grid point because the tectonic stressing rate will not be optimally aligned with the heterogeneous array of failure plane orientations. To initialize the system for background seismicity prior to a main shock, we use only those failure orientations/slip directions with positive $\dot{S}_{r}$. Equation 2 can now be rewritten as

$$
R(t)=r \frac{\gamma_{0}}{\gamma(t)} .
$$

The change in $\gamma$ due to a static stress change, $\Delta \boldsymbol{\sigma}^{F}(\mathbf{x})$, at the time of the main shock is given by the solution to Eq. 3 for a step in stress

$$
\gamma_{1}=\gamma_{0} \exp \left(-\frac{\Delta S^{F}}{a \sigma_{n}}\right)
$$

where $\Delta S^{F}$ is the Coulomb stress change from $\Delta \boldsymbol{\sigma}^{F}(\mathbf{x})$ resolved into $\left(\mathbf{n}^{R L}, \mathbf{l}^{R L}\right)$ and $\left(\mathbf{n}^{L L}, \mathbf{l}^{L L}\right)$. The evolution of $\gamma$ with time following the stress step is given by the solution to Eq. 3 for a constant stress rate, $\dot{S}_{r}$,

$$
\gamma_{2}(t)=\left(\gamma_{1}-\frac{1}{\dot{S}_{r}}\right) \exp \left(-\frac{t}{t_{a}}\right)+\frac{1}{\dot{S}_{r}}
$$

where $t_{a}=\frac{a \sigma_{n}}{\dot{S}_{r}}$ is the aftershock duration. In modeling aftershock sequences, previous studies (DIETERICH, 1994; Dieterich, 2007; TODA et al., 1998) typically found values of $t_{a}$ in the range of 2-10 years. The values $\gamma_{2}(t)$ for the two possible failure planes/slip directions at each point in the grid can then be used with Eq. 10 to calculate the time evolution of seismicity rate, $R$, at each point.

Last, to generate the synthetic aftershock catalogs, we use a random non-stationary Poissonian process with the seismicity rate, $R$, to sample the failure planes/slip directions $\left(\mathbf{n}^{R L}, \mathbf{l}^{R L}\right)$ and $\left(\mathbf{n}^{L L}, \mathbf{l}^{L L}\right)$. To simulate measurement uncertainty seen in real focal mechanism data, a random normal noise is added to the focal mechanisms orientations with a mean angular spread of $12^{\circ}$ to simulate fairly high quality focal mechanisms, following the procedure of SмIтH (2006) and Smith and Heaton (2010).

\section{Overview of Results}

In the following, we present results for synthetic seismicity with spatially uniform stressing at a constant rate for aftershocks resulting from spatially uniform static stress changes and aftershocks resulting from spatially variable static stress changes from slip on a finite, geometrically complex fault. Three principal stress orientations are involved: (1) The orientation for the spatially uniform, $\boldsymbol{\sigma}^{B}$, (2) the orientation of the far-field tectonic stressing rate, $\dot{\boldsymbol{\sigma}}^{T}$, and (3) the orientation of the spatial mean of the static stress change defined in a region, $\Delta \overline{\boldsymbol{\sigma}}^{F}(\mathbf{x})$, from the main shock. For the case of a spatially uniform static stress change, $\Delta \boldsymbol{\sigma}^{F}$ (see Figs. 3, 4, and 5), $\dot{\boldsymbol{\sigma}}^{T}$ is aligned with $\boldsymbol{\sigma}^{B}$, but $\Delta \boldsymbol{\sigma}^{F}$ is misaligned. The misalignment of $\Delta \boldsymbol{\sigma}^{F}$ is used to test for possible biasing effects in the rotation of the inferred maximum horizontal compressive stress, $\sigma_{H}$, from stress inversions. All stress inversions are done using a bootstrapping technique with Andy Michael's program "slick" (MichaEL, 1984, 1987). When slip on a finite fault is 
(a) Seismicity from Uniform Random Samples of the Initial Stress, $\sigma^{0}(x)$, With Spatial Mean, $\sigma^{B}$
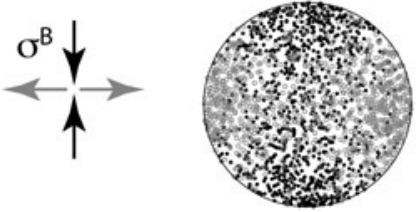

(b)

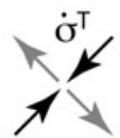

Inter-Seismic, Background Seismicity with Stress Rate, $\dot{\sigma}^{\top}$

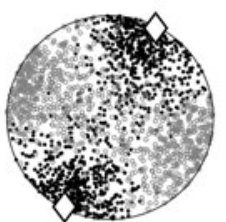

Uniform Random Samples on Top of Coulomb

Stress for Planes Aligned with a Horizontal Fault

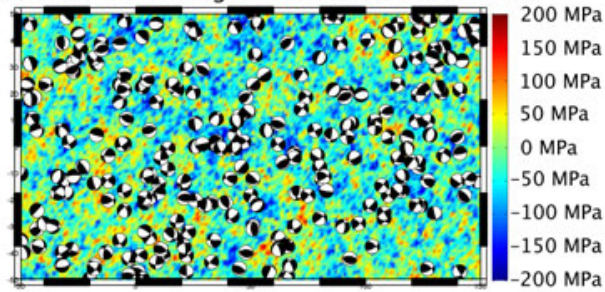

Inter-Seismic Seismicity on Top of Coulomb Stress for Planes Aligned with a Horizontal Fault

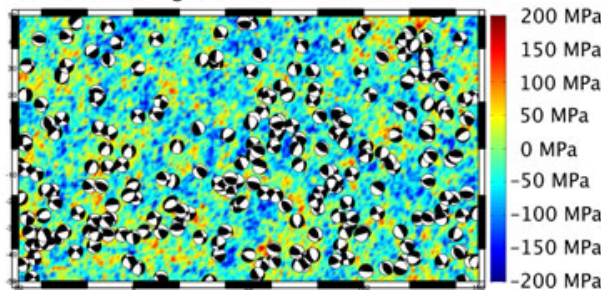

Figure 2

In $\mathbf{a}$, a uniform random sampling of the heterogeneous stress field, $\boldsymbol{\sigma}^{0}(\mathbf{x})$, with its associated optimally oriented failures, produces the synthetic seismicity. In $\mathbf{b}$, a spatially homogeneous stress rate $\dot{\boldsymbol{\sigma}}^{T}$ is applied at $45^{\circ}$ relative to $\boldsymbol{\sigma}^{B}$. Note that the stereographic projections of $\dot{\boldsymbol{\sigma}}^{T}=$ $0.02 \mathrm{MPa} /$ year and $\boldsymbol{\sigma}^{B}=50 \mathrm{MPa}$ are not to scale. They simply show the orientation of the maximum and minimum compressive principal stresses. Seismicity is generated as a random Poissonian process, where the seismicity rate at each point in the grid is governed by the resolved Coulomb stressing history on heterogeneous failure planes/slip directions through the rate-state seismicity equations. The resultant inferred $\sigma_{H}$ from a stress inversion of focal mechanism is rotated approximately $20^{\circ}$ relative to the same quantities in a. This bias toward the stressing rate reproduces an effect described by Sмітн (2006) and Sмітн and HeAton (2010). Our calculation, however, uses rate-state seismicity equations and Coulomb stress, as opposed to a plastic failure criterion

used to create the mainshock static stress change, the misalignment of $\Delta \boldsymbol{\sigma}^{F}(\mathbf{x})$ is spatially variable.

\section{Background Seismicity at Constant Stressing Rate}

The first model we examine is that of steady-state seismicity at a constant stressing rate (Fig. 2). In this model, the heterogeneous stress field, $\boldsymbol{\sigma}^{0}(\mathbf{x})$, has a spatial mean with the most compressive stress, $\sigma_{1}$, oriented $\mathrm{N}-\mathrm{S}$ and the least compressive stress, $\sigma_{3}$, oriented $\mathrm{E}-\mathrm{W}$. The heterogeneity parameters used are $(\alpha=0.7, H R=2.5)$, and the deviatoric stress amplitude is $50 \mathrm{MPa}$. The heterogeneous population of faults, optimally oriented for initial stress, $\boldsymbol{\sigma}^{0}(\mathbf{x})$, and coefficient of friction, $\mu=0.4$, is subjected to a homogeneous stressing rate, $\dot{\boldsymbol{\sigma}}^{T}$, of amplitude $0.02 \mathrm{MPa} /$ year. $\dot{\boldsymbol{\sigma}}^{T}$ has a maximum compressive principal stressing rate, $\dot{\sigma}_{1}$, aligned with $\left(A z .=N 45^{\circ} E, \quad \delta=0^{\circ}\right)$ and a least compressive principal stressing rate, $\dot{\sigma}_{3}$, aligned with $\left(A z .=N 45^{\circ} \mathrm{W}, \delta=0^{\circ}\right)$.
Figure 2a illustrates focal mechanisms that would arise from a spatially uniform sample of the failure planes/slip directions in the 3-D grid. The sampled failure planes/slip directions reflect the spatially heterogeneous initial stress, $\boldsymbol{\sigma}^{0}(\mathbf{x})$, which has a spatial mean $\approx \boldsymbol{\sigma}^{B}$. Since we allow for both right-lateral and left-lateral failures with $\mu=0.4$, we have clusters of $\mathrm{P}-\mathrm{T}$ axes on either side of the $\boldsymbol{\sigma}^{B}$ orientation; however, the orientation heterogeneity is large enough to smear together the two clusters so it appears that the average $\mathrm{P}$ axis is aligned with most compressive principal stress, $\sigma_{1}$, for $\boldsymbol{\sigma}^{B}$ and the average $\mathrm{T}$ axis is aligned with the least compressive principal stress, $\sigma_{3}$, for $\boldsymbol{\sigma}^{B}$.

Figure $2 \mathrm{~b}$ shows the seismicity and focal mechanisms generated by the model in response to a stressing rate, $\dot{\boldsymbol{\sigma}}^{T}$, resolved onto the failure planes/slip directions from $\boldsymbol{\sigma}^{0}(\mathbf{x})$ with spatial mean $\approx \boldsymbol{\sigma}^{B}$; namely, $\dot{\boldsymbol{\sigma}}^{T}$ is resolved onto failure planes/slip directions defined by $\left(\mathbf{n}^{R L}, \mathbf{l}^{R L}\right)$ and $\left(\mathbf{n}^{L L}, \mathbf{l}^{L L}\right)$ to calculate the background Coulomb stressing rate, $\dot{S}_{r}$, on the two possible failure planes/slip directions at each 
grid point. From Eq. 10, the relative seismicity rates are $\propto \dot{S}_{r}$, producing spatial variability in the background seismicity rate. Last, events are assumed to be random Poissonian processes non-stationary seismicity rates; hence, each potential failure plane/slip direction, with positive $\dot{S}_{r}$, provides a possible source of seismicity governed by its associated seismicity rate. Using an exponential random number generator to produce failure times for each potential seismicity source, we plot $\sim$ the first 1,000 events. This creates focal mechanism $\mathrm{P}-\mathrm{T}$ axes in Fig. $2 \mathrm{~b}$ rotated approximately $20^{\circ}$ away from $\boldsymbol{\sigma}^{B}$, toward the stressing rate, $\dot{\boldsymbol{\sigma}}^{T}$. The rotation is purely a result of biased sampling of the failure planes that are oriented toward the optimal direction for the stressing rate, $\dot{\boldsymbol{\sigma}}^{T}$, rather than initial stress, $\boldsymbol{\sigma}^{0}(\mathbf{x})$. We employ Coulomb stress and rate-state seismicity equations to generate seismicity and reproduce the interseismic biasing effect found by Sмiтh (2006) and Sмiтh and Heaton (2010) who used a plastic failure criterion.

\section{Spatially Uniform Static Stress Change, $\Delta \boldsymbol{\sigma}^{F}$}

We next examine a simple model with a spatially uniform static stress, $\Delta \boldsymbol{\sigma}^{F}$, of deviatoric amplitude, $2 \mathrm{MPa}$. Again, the stress heterogeneity parameters are $(\alpha=0.7, H R=2.5)$ for $\boldsymbol{\sigma}^{0}(\mathbf{x}) \cdot \boldsymbol{\sigma}^{B}$ has a $50 \mathrm{MPa}$ deviatoric stress amplitude, and $\dot{\boldsymbol{\sigma}}^{T}$ has a $0.02 \mathrm{MPa} /$ year deviatoric stress amplitude. The principal axes of the stress parameters $\boldsymbol{\sigma}^{B}$ and $\dot{\boldsymbol{\sigma}}^{T}$ are co-axially aligned with a $\sigma_{1}$ direction $\left(A z .=N 45^{\circ} E, \delta=0^{\circ}\right)$ and a $\sigma_{3}$ direction $\left(A z .=N 45^{\circ} \mathrm{W}, \delta=0^{\circ}\right)$; however, the orientation of $\Delta \boldsymbol{\sigma}^{F}$ is varied with respect to the other stresses, which permits explicit tests for rotation of $\sigma_{H}$ from stress inversions of focal mechanisms.

In Fig. 3, we simulate a series of models, using various differential angles between $\Delta \boldsymbol{\sigma}^{F}$ and $\boldsymbol{\sigma}^{B}$. Using Eqs. 10, 11, and 12, aftershock seismicity rates are evaluated at the same time shortly following the stress step $\left(10^{-3} t_{a}\right)$, which would be a few days to a week for a typical aftershock sequence. Events arise when we randomly generate a set of failure times based on the spatially varying seismicity rates, extract events with failure times $\leq 10^{-3} t_{a}$, and plot $\mathrm{P}-\mathrm{T}$ axes for 1,000 of these events with times $\leq 10^{-3} t_{a}$. A stress inversion is then applied to this aftershock seismicity for each differential angle between $\Delta \boldsymbol{\sigma}^{F}$ and $\boldsymbol{\sigma}^{B}$ to compute the inferred orientation of the maximum horizontal compressive stress, $\sigma_{H}$. The P-T plots show samples of this synthetic seismicity for varying differential angles, where the open diamonds are the inferred $\sigma_{H}$ orientations for the background seismicity given the $\boldsymbol{\sigma}^{B}$ and $\dot{\boldsymbol{\sigma}}^{T}$ orientations, and the black circles are the inferred $\sigma_{H}$ orientations one would obtain from aftershock focal mechanisms at $t=10^{-3} t_{a}$; hence, any angular difference between the black circles and open diamonds indicates a rotation of the inferred $\sigma_{H}$. Below the P-T plots are two lines, a solid line representing the rotation of inferred $\sigma_{H}$ from stress inversions of aftershock seismicity, which we call an "apparent" rotation, and a dashed line that represents the "true" rotation one would expect from the summation of stress, $\boldsymbol{\sigma}^{B}+\Delta \boldsymbol{\sigma}^{F}$.

We find major differences between the true stress rotation and the apparent stress rotation from focal mechanism inversions. While the maximum true stress rotation due to the stress step is $<2^{\circ}$, the maximum apparent rotation from focal mechanisms is $>30^{\circ}$. This large apparent rotation occurs because the change in seismicity rate depends exponentially on the change in stress from Eq. 11. Consequently, planes that are toward the optimal orientation for $\Delta \boldsymbol{\sigma}^{F}$ experience a much greater increase in seismicity than unfavorably oriented planes.

Smith (2006) and Smith and Heaton (2010) showed that biasing of stress orientations, as determined from stress inversions of focal mechanisms, depends on the value of $H R$ up to some limit, $H R \approx 10$. If $H R=0.0$, there is no biasing due to stress heterogeneity, and as $H R$ increases, the biasing of inferred stress orientations also increases. Therefore, if $H R=0.0$ in our aftershock simulations, there should be no biasing, and the maximum apparent rotation should be close to zero. (Remember that in our end-member simulations, all changes in $\sigma_{H}$ and $\beta$ are due entirely to changes in the biased sampling of pre-set failure planes/slip directions plus minimal measurement error. There is no updating of the pre-set failure planes/slip directions due to true stress changes.) Then as $H R$ increases, we would expect the maximum apparent rotation to also increase. 


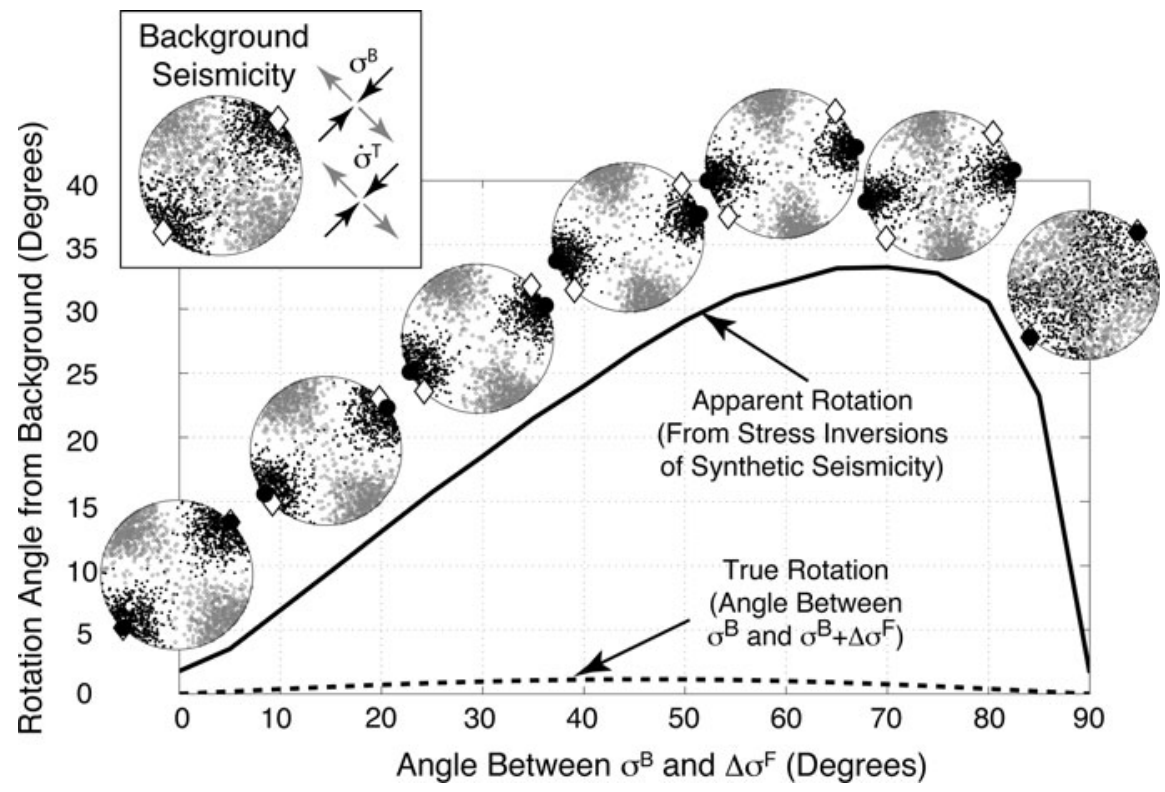

Figure 3

Plot of "apparent" rotation of the maximum horizontal compressive stress, $\sigma_{H}$, from inversions of synthetic aftershock seismicity versus expected "true" rotation from the static stress change, $\Delta \boldsymbol{\sigma}^{F}$. $\boldsymbol{\sigma}^{B}$ represents the approximate spatial mean of the initial stress field, and $\Delta \boldsymbol{\sigma}^{F}$ represents the static stress change. The principal axes of the stressing rate, $\dot{\boldsymbol{\sigma}}^{T}$, are aligned with those of $\boldsymbol{\sigma}^{B}$. In this example, $\Delta \boldsymbol{\sigma}^{F}$ is spatially uniform. Using the stress parameters described in the text, aftershock seismicity is evaluated at the same time, $10^{-3} t_{a}$, for various $\boldsymbol{\sigma}^{B}$ and $\Delta \boldsymbol{\sigma}^{F}$ angular differences. The "true" rotation of the stress field is plotted with the dashed line, and the "apparent" rotation of the maximum horizontal compressive stress, $\sigma_{H}$, from stress inversions of aftershock focal mechanisms is drawn with the solid line. Plots of synthetic aftershock P-T axes are plotted above the solid line where the black circles show the orientation of inferred $\sigma_{H}$ for this data, and the open diamonds show the background seismicity $\sigma_{H}$ orientation; hence, the angular difference between the circles and diamonds also show the "apparent" rotation of $\sigma_{H}$. The "apparent" rotation is considerably larger than the "true" rotation at every point

In Figs. 4 and 5, we now explore the time evolution of aftershock seismicity for our model with a spatially uniform stress step, $\Delta \boldsymbol{\sigma}^{F}$, by setting the angle between $\Delta \boldsymbol{\sigma}^{F}$ and $\boldsymbol{\sigma}^{B}$ to $45^{\circ}$, and using rate-state seismicity equations to evaluate seismicity rates at different times. The seismicity rate, normalized by the background seismicity rate is plotted as a function of time in Fig. 4. It shows approximately Omori law behavior, with a slope of $1 / t^{p}$, where $p \approx 0.9$. Above the seismicity rate are plots of $\mathrm{P}-\mathrm{T}$ axes from synthetic mechanisms and inferred $\sigma_{H}$ orientations as a function of time. The rotated focal mechanism solutions produce an initial jump in the inferred $\sigma_{H}$ orientation immediately after the applied static stress change, $\Delta \boldsymbol{\sigma}^{F}$, as seen by the angular difference between the open diamonds and black circles. Again the open diamonds represent the inferred $\sigma_{H}$ orientation of background seismicity, and the black circles represent the inferred $\sigma_{H}$ orientations from stress inversions of aftershocks. The angular difference between the open diamonds and black circles visually demonstrates the "apparent" rotation of $\sigma_{H}$. With time, the $\sigma_{H}$ "apparent" rotation decays as $\sigma_{H}$ returns to the reference orientation seen for background seismicity. The "apparent" rotation of $\sigma_{H}$, with a decay back to its original value, is explicitly plotted in Fig. 5 along with temporal changes in the mean misfit angle, $\beta$. In Fig. 5, $\beta$ initially decreases as biasing effects kick in and then increases in time.

\section{Spatially Variable Static Stress Change, $\Delta \boldsymbol{\sigma}^{F}(\boldsymbol{x})$, Through Slip on Finite Faults}

We model aftershock patterns that might be expected from $10 \mathrm{~m}$ uniform slip on finite faults and their associated spatially nonuniform static stress changes, $\Delta \boldsymbol{\sigma}^{F}(\mathbf{x})$. The finite faults run $100 \mathrm{~km}$ long in the $\mathrm{x}$ direction and $20 \mathrm{~km}$ deep in the $\mathrm{z}$ direction, where the dimensions of the simulation space is 


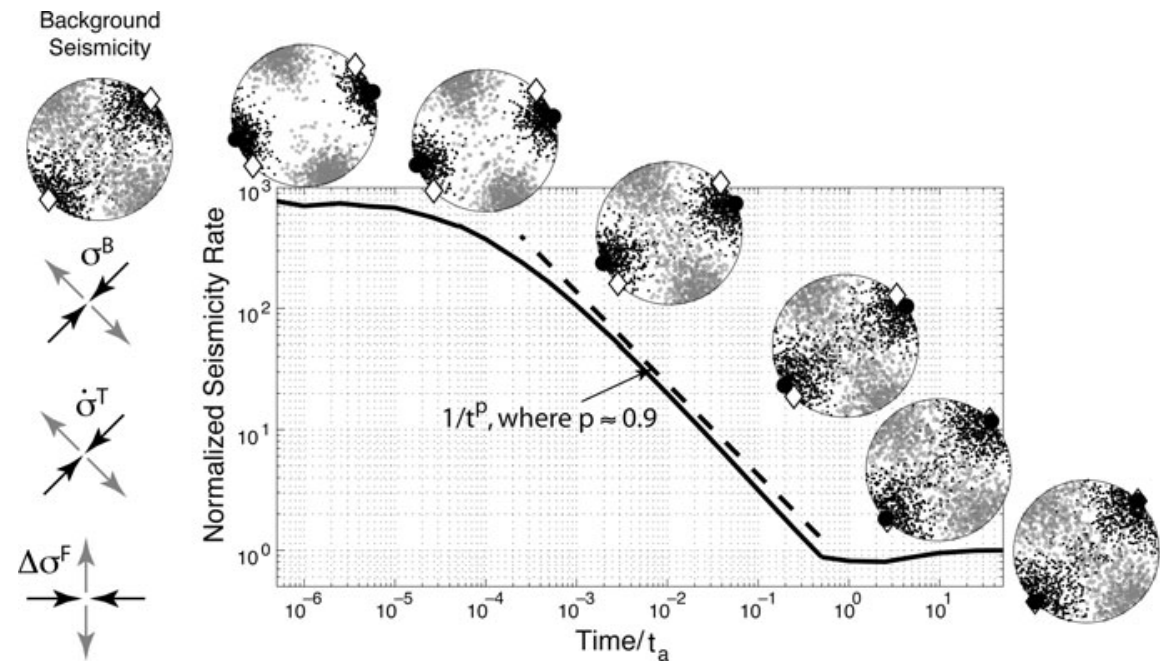

Figure 4

Evolution of seismicity and focal mechanisms with time following a stress step. Same experimental set-up as in Fig. 3, only the angular difference between $\boldsymbol{\sigma}^{B}$ and $\Delta \boldsymbol{\sigma}^{F}$ is fixed to $45^{\circ}$. Plots of the focal mechanism P-T axes show snapshots of the aftershocks at different times. Open diamonds show the inferred $\sigma_{H}$ orientation for the background seismicity, and the black circles show the inferred $\sigma_{H}$ orientation from a stress inversion of the aftershocks at each time. There is an initial step rotation of $\sigma_{H}$ at the onset of the spatially uniform stress step and then a decay as time progress. The seismicity rate, normalized by the background seismicity, has approximately Omori law-like behavior one would expect from rate-state controlled processes. Note that the stereographic projections of $\dot{\boldsymbol{\sigma}}^{T}=0.02 \mathrm{MPa} / \mathrm{year}, \boldsymbol{\sigma}^{B}=50 \mathrm{MPa}$, and

$$
\Delta \boldsymbol{\sigma}^{F}=2 \mathrm{MPa} \text { are not to scale }
$$
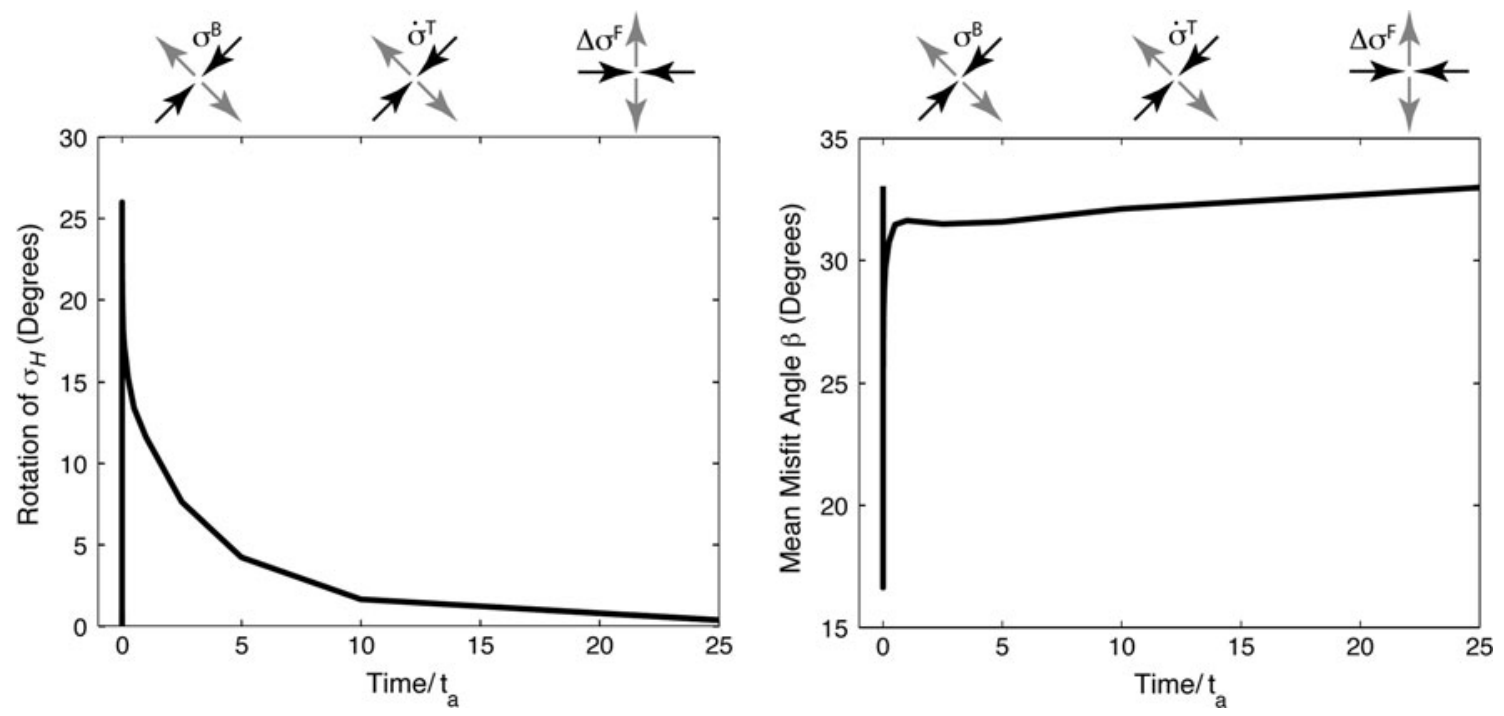

Figure 5

Rotation of $\sigma_{H}$ and change in the mean misfit angle, $\beta$, from focal mechanism solutions using the synthetic seismicity from Fig. 4 . The rotation of $\sigma_{H}$ decays rapidly at first; hence, estimates of $\sigma_{H}$ from stress inversions might only measure a $10^{\circ}-15^{\circ}$ rotation at the onset of the step stress change rather than the $27^{\circ}$ rotation shown. The mean misfit angle, $\beta$, decreases at first, then increases, the opposite of what is seen in real data; however, the stress change applied for these figures is spatially uniform

$200 \mathrm{~km} \times 100 \mathrm{~km} \times 50 \mathrm{~km}$, with $1 \mathrm{~km}$ resolution. We use both a planar fault and a single geometrically complex fault with fractal-like topography. The geometrically complex fault used in the simulations has surface roughness amplitude that goes as Amplitude $\propto \mathrm{B} l^{H}$, as used in Dieterich and SMith (2009). 
In this case, the exponent $H$ is set to 1.0, which gives a self-similar roughness, and the rms slope has been set to $B=0.07$. The initial stress, $\boldsymbol{\sigma}^{0}(\mathbf{x})$, again has stress heterogeneity parameters, $\quad(\alpha=0.7, H R=$ $2.5)$, and a spatial mean deviatoric amplitude of $50 \mathrm{MPa}$. The stressing rate $\dot{\boldsymbol{\sigma}}^{T}$ has a $0.02 \mathrm{MPa} /$ year deviatoric stress amplitude.

The orientations of $\boldsymbol{\sigma}^{B}$ and $\dot{\boldsymbol{\sigma}}^{T}$ with respect to the fault and each other significantly affect the results; therefore, we carefully choose these orientations for the simulations. For the planar fault, which serves as our "Reference" model, $\boldsymbol{\sigma}^{B}$ and $\dot{\boldsymbol{\sigma}}^{T}$ have principal stress axes $\left(A z .=N 45^{\circ} E, \delta=0^{\circ}\right)$ for the $\sigma_{1}$ direction and $\left(A z .=N 45^{\circ} W, \delta=0^{\circ}\right)$ for the $\sigma_{3}$ direction. For the geometrically complex or "Rough" fault, we examine three different scenarios. In "Rough" fault model \#1, the principal axes of $\boldsymbol{\sigma}^{B}$ and $\dot{\boldsymbol{\sigma}}^{T}$ are the same as the planar fault, "Reference" model, where the most compressive principal stress axes for $\boldsymbol{\sigma}^{B}$ and $\dot{\boldsymbol{\sigma}}^{T}$ are at $45^{\circ}$ with respect to the overall trend of the fault. In "Rough" fault model \#2, $\dot{\boldsymbol{\sigma}}^{T}$ has its maximum compressive principal direction, $\dot{\sigma}_{1}, \perp$ to the fault trend so that $\dot{\sigma}_{1}$ is aligned with $(A z .=$ $N 0^{\circ} E, \delta=0^{\circ}$ ) and $\dot{\sigma}_{3}$ is aligned with $(A z .=$ $N 90^{\circ} E, \delta=0^{\circ}$ ). Last, for "Rough" fault model \#3, $\boldsymbol{\sigma}^{B}$ has its maximum compressive principal direction, $\sigma_{1}, \perp$ to the fault trend so that $\left(A z .=N 0^{\circ} E, \delta=0^{\circ}\right)$ for its maximum compressive principal stress, $\sigma_{1}$, and $\left(A z .=N 90^{\circ} E, \delta=0^{\circ}\right)$ for its minimum compressive principal stress direction, $\sigma_{3}$.

Figures 6 and 7 show aftershock distributions for all four finite fault simulations. The top three rows, a, $\mathrm{b}$, and $\mathrm{c}$, show the instantaneous aftershock spatial distributions based on seismicity rates at a given instant in time. Specifically, we use rate-state friction equations to evaluate the seismicity rates at each point in the 3-D model region for the specified time. Then using these instantaneous rates, a random Poissonian process generates 2,000 events. The bottom row, d, for both Figs. 6 and 7, shows a normalized cumulative aftershock spatial distribution at $t=0.1 t_{a}$. This is a summation of all the aftershock seismicity that has occurred up until $t=0.1 t_{a}$, normalized by the background seismicity rate. In a sense, rows a-c in Figs. 6 and 7 plot the un-normalized probability density functions (PDFs) for seismicity at different time slices as a function of space, and row d plots the normalized time integration of the spatial pdfs until time, $t=0.1 t_{a}$.

Aftershocks for slip on the planar fault "Reference" model versus slip on the "Rough" fault model \#1 are compared in Fig. 6. Again, $\boldsymbol{\sigma}^{B}$ and $\dot{\boldsymbol{\sigma}}^{T}$ have their most compressive principal stress at $45^{\circ}$ with respect to the overall fault trend for both the "Reference" model and "Rough" fault model \#1. The instantaneous aftershock seismicity concentrates initially on the Coulomb stress increase areas then migrates with time to an approximately spatially uniform distribution, which is the background seismicity spatial distribution in these models. Interestingly, even for the "Reference" model that has uniform slip on a planar fault, a few events occur in the stress shadow zone. This occurs because the pre-existing spatially heterogeneous stress field, $\boldsymbol{\sigma}^{0}(\mathbf{x})$, provides sufficient potential failure orientation heterogeneity that a few planes will be activated. Induced aftershock seismicity in the traditional stress shadow zone is even more pronounced for "Rough" fault model \#1, especially near or on the fault trace. Slip on the geometrically complex fault produces small-scale stress asperities close to the fault trace, including zones of Coulomb stress increases that can especially generate aftershock seismicity.

Figure 7 illustrates the two examples where either $\boldsymbol{\sigma}^{B}$ or $\dot{\boldsymbol{\sigma}}^{T}$ have their most compressive principal stress axis $\perp$ with respect to the overall trend of the fault. "Rough" fault model \#2 is shown on the left, where $\dot{\boldsymbol{\sigma}}^{T}$ has its most compressive principal stress rate oriented $\perp$ to the fault. "Rough" fault model \#3 is shown on the right, where $\boldsymbol{\sigma}^{B}$ has its most compressive principal stress oriented $\perp$ to the fault. A significant percentage of the initial aftershock seismicity for model \#2 occurs in the stress shadow zone, demonstrating a distinctly different aftershock pattern from model \#1 in Fig. 6 when both $\boldsymbol{\sigma}^{B}$ and $\dot{\boldsymbol{\sigma}}^{T}$ are aligned $45^{\circ}$ with respect to the fault. The aftershock distribution for model \#3 in Fig. 7, however, looks very similar to the spatial distribution seen for model \#1 in Fig. 6. Of interest, model \#3, which has aftershock seismicity more realistic than that seen in model \#2, is similar to some models of the Southern San Andreas (TownEND and ZoBACK, 2004), where the maximum compressive principal stress direction of 
Reference Model (Planar Fault)
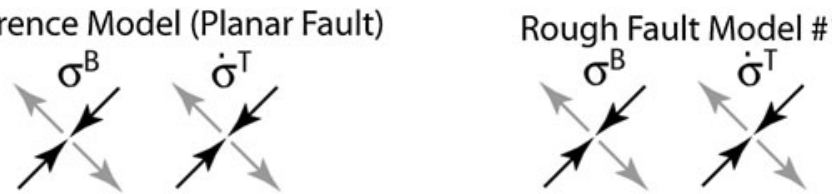

Spatial Distribution of Instantaneous Aftershock Seismicity
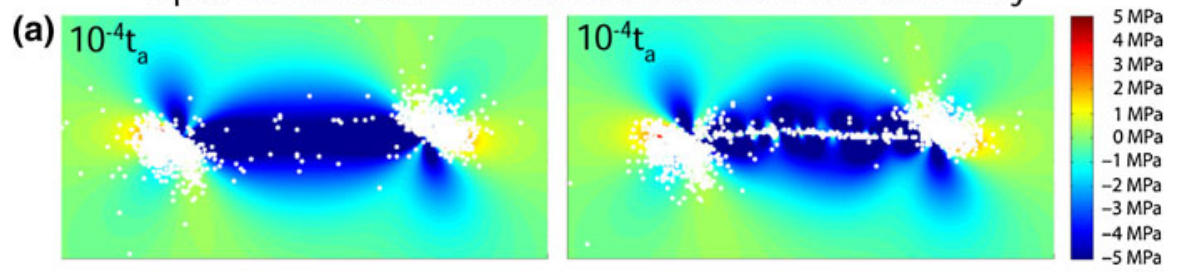

(b)
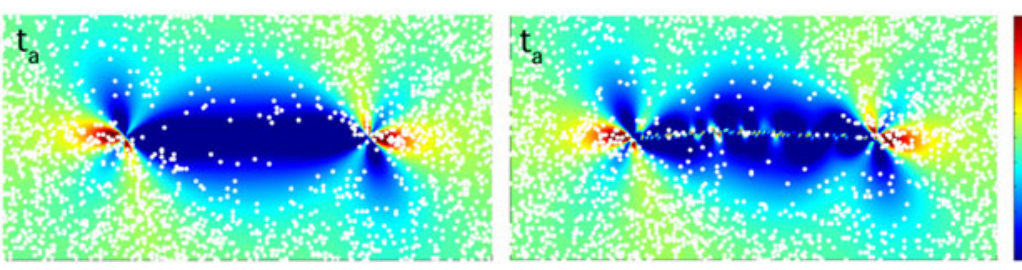

$5 \mathrm{MPa}$

$4 \mathrm{MPa}$

$3 \mathrm{MPa}$

$2 \mathrm{MPa}$

$1 \mathrm{MPa}$

$0 \mathrm{MPa}$

$-1 \mathrm{MPa}$

$-2 \mathrm{MPa}$
$-3 \mathrm{MPa}$

$-4 \mathrm{MPa}$

(c)
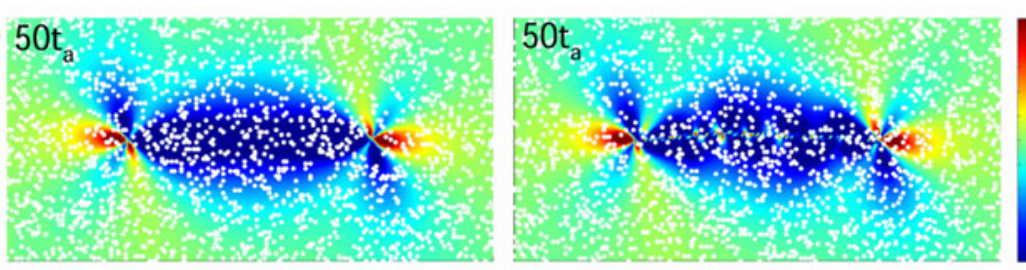

$-5 \mathrm{MPa}$

$5 \mathrm{MPa}$

$3 \mathrm{MPa}$

$2 \mathrm{MPa}$

$1 \mathrm{MPa}$

$0 \mathrm{MPa}$
$-1 \mathrm{MPa}$

$-1 \mathrm{MPa}$

$-2 \mathrm{MPa}$

$-3 \mathrm{MPa}$

Spatial Distribution of Cumulative Aftershock Seismicity
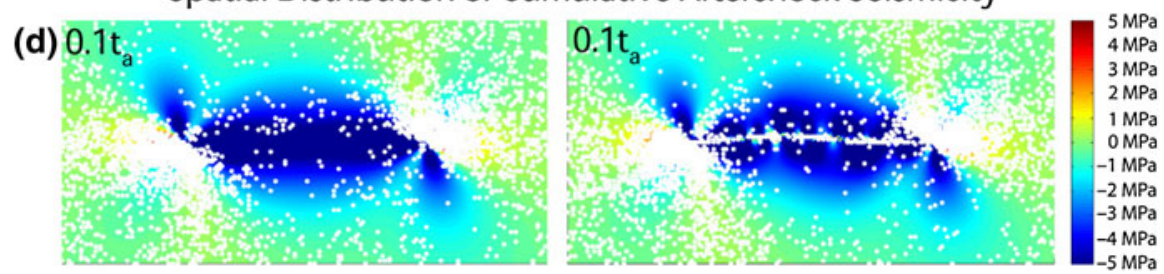

Figure 6

Aftershock seismicity for $10 \mathrm{~m}$ uniform slip on a planar fault and $10 \mathrm{~m}$ uniform slip on a geometrically complex fault. $\dot{\boldsymbol{\sigma}}^{T}$ and $\boldsymbol{\sigma}^{B}$ orientated $45^{\circ}$ with respect to the overall fault trend in both models. Note that the stereographic projections of $\dot{\boldsymbol{\sigma}}^{T}=0.02 \mathrm{MPa} /$ year and $\boldsymbol{\sigma}^{B}=50 \mathrm{MPa}$ are not to scale. The color scale goes from $\pm 5 \mathrm{MPa}$, and the Coulomb stress change is calculated for planes parallel to the planar fault. For each panel in $\mathbf{a}, \mathbf{b}$, and $\mathbf{c}$, seismicity rates are evaluated at the specified time. Then 2,000 random events are generated using a non-stationary random Poissonian process with the instantaneous seismicity rates. The panels in $\mathbf{d}$ show a normalized cumulative aftershock seismicity for $t=0.1 t_{a}$. The heterogeneous failure plane population enables the "Reference" model, with uniform slip on a planar fault, to experience a few failures in the stress shadow zone. Stress asperities from slip on the geometrically complex fault, in "Rough" model \#1, create aftershock seismicity directly on or near the fault trace. Last, seismicity initially concentrates near the Coulomb stress increase areas and eventually becomes spatially uniform as the system transitions to the background seismicity state

$\boldsymbol{\sigma}^{B}$ is inferred to be perpendicular to the fault. Again, as in Fig. 6, there is a migration with time to an approximately spatially uniform seismicity distribution, which is the background seismicity distribution for our models.

Figures 9 and 10 present seismicity rates, rotations of the inferred maximum horizontal compressive stress, $\sigma_{H}$, from stress inversions, and changes in the stress inversion mean misfit angle, $\beta$, for "Rough" fault models \#1-\#3. To employ the synthetic data in a way that is similar to what is done in stress rotation studies, these quantities are plotted for the entire upper $15 \mathrm{~km}$ of the modeled region and for a subsection close to the fault trace (see Fig. 8). 
Rough Fault Model \#2
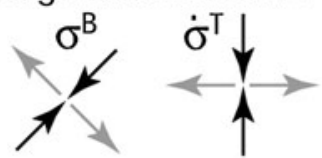

Rough Fault Model \#3

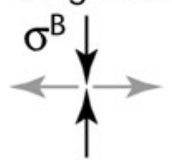

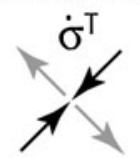

Spatial Distribution of Instantaneous Aftershock Seismicity

(a)
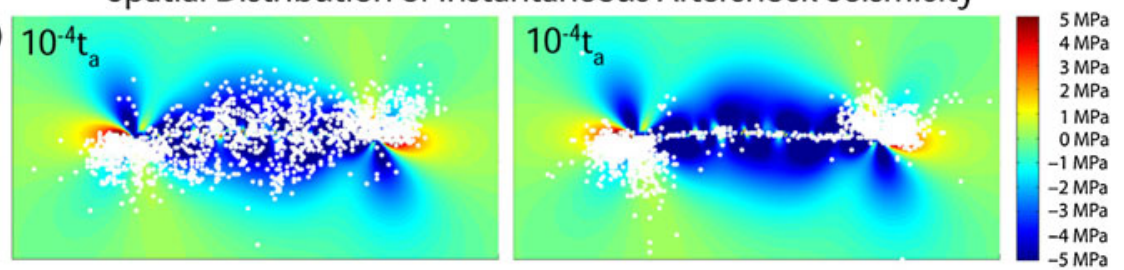

(b)

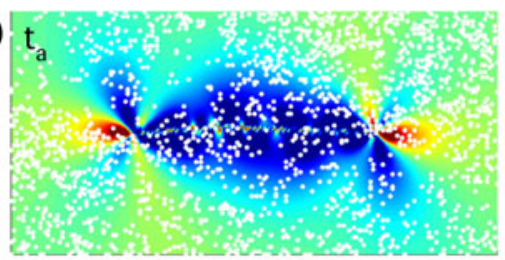

(c)
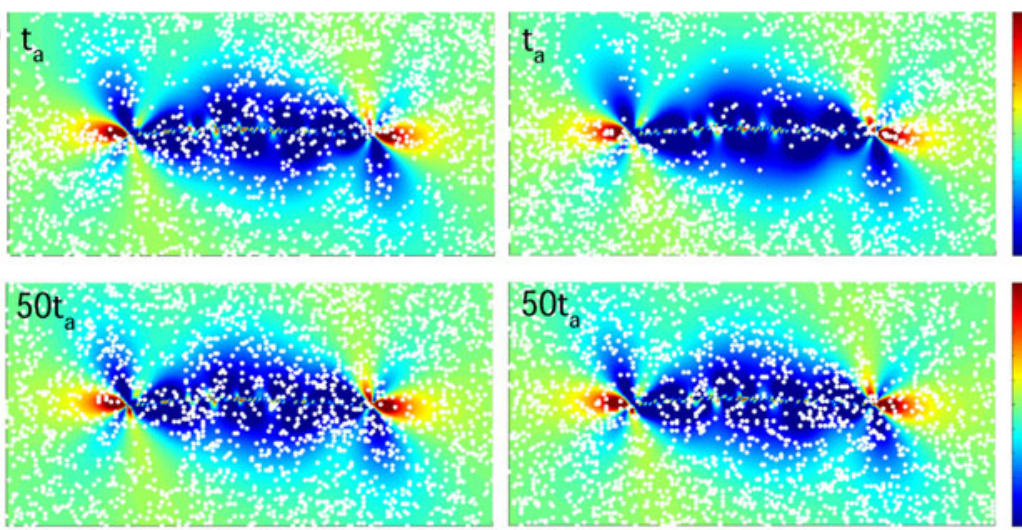

$5 \mathrm{MPa}$

$4 \mathrm{MPa}$

$3 \mathrm{MPa}$

$2 \mathrm{MPa}$

$\mathrm{OMPa}$

$-1 \mathrm{MPa}$

$-2 \mathrm{MPa}$

$-3 \mathrm{MPa}$

$-4 \mathrm{MPa}$

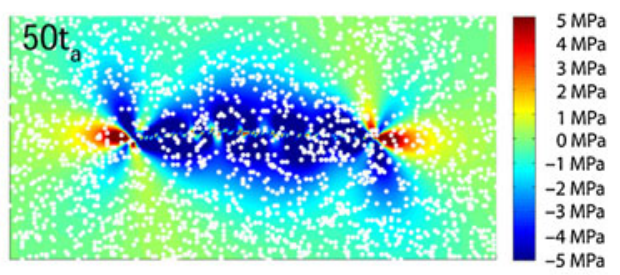

Spatial Distribution of Cumulative Aftershock Seismicity

(d)
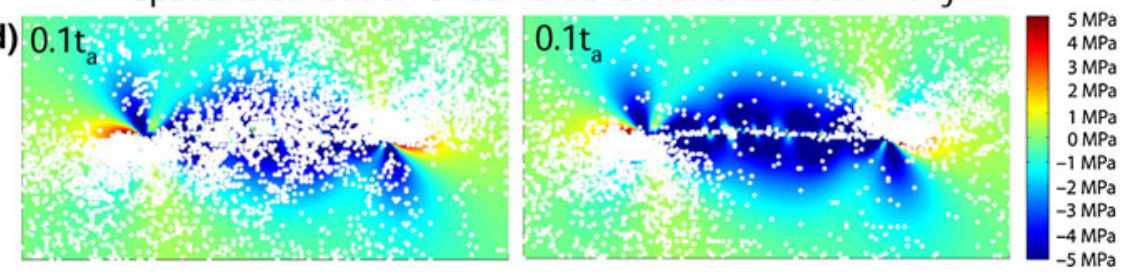

Figure 7

Similar to Fig. 6, only this time either $\boldsymbol{\sigma}^{B}$ or $\dot{\boldsymbol{\sigma}}^{T}$ have their maximum compressive principal stress $\perp$ with respect to the major fault trend. For "Rough" fault model \#2, the principal compressive axis of $\dot{\boldsymbol{\sigma}}^{T}$ is $\perp$ to the overall fault trend, and for "Rough" fault model \#3, the principal compressive axis of $\sigma^{B}$ is $\perp$ to the overall trend of the fault. The aftershock seismicity distribution for model \#2 has a large percentage of its seismicity in the stress shadow region; whereas, the aftershock seismicity for model \#3 looks fairly similar to model \#1 in Fig. 6 , where both $\boldsymbol{\sigma}^{B}$ and $\dot{\boldsymbol{\sigma}}^{T}$ are aligned at $45^{\circ}$ with respect to the fault

Seismicity rates and the behavior of aftershock seismicity as a function of time are shown in Fig. 9. The seismicity rates, normalized by the background rate for the upper $15 \mathrm{~km}$ of the modeled region, approximately follow Omori law, $1 / t^{p}$, where $p \approx 0.87$ for the upper $15 \mathrm{~km}$ (dashed line) and $p \approx 0.87$ for the subsection (solid line). For the subsection, especially models \#1 and \#3, the seismicity rate bottoms out at $t_{a}$ with a value significantly below its normalized background rate of $\approx 0.09$.
(Note that the background rate for the subsection will be less than 1.0 since the subsection represents a fraction of the upper $15 \mathrm{~km}$.) Eventually, the seismicity rate for the subsection climbs back up for large times, at approximately $t=\frac{\Delta S^{F}}{\dot{S}_{r}}$. This effect has been seen before with models that use rate-state equations when the static stress change is in the opposite direction of the stressing rate (SCHAFF et al., 1998); hence, the static stress change temporarily suppresses the seismicity rate. 


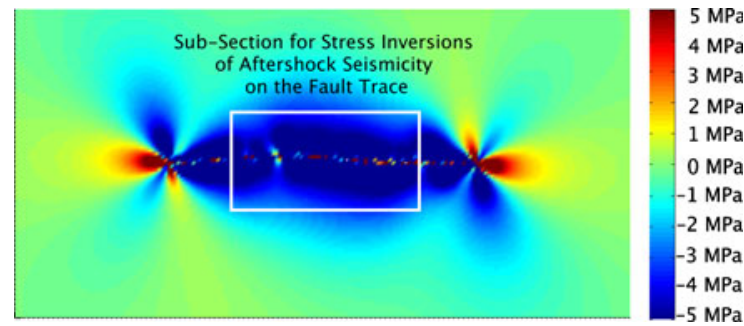

Figure 8

The subsection of the model region used for creating the $\mathrm{P}-\mathrm{T}$ plots in Fig. 9 and the solid lines in Figs. 9 and 10. It is intended to capture seismicity close to or on top of the fault trace similar to aftershock studies

The P-T plots in Fig. 9 represent instantaneous aftershock seismicity from the subsection at different snapshots in time. The open diamonds represent the inferred $\sigma_{H}$ orientation from stress inversions of background seismicity, and the solid circles represent the inferred $\sigma_{H}$ orientation from stress inversions of aftershock seismicity; therefore, the angular differences between the diamonds and circles represent rotations of the inferred $\sigma_{H}$ for the subsection. When $\boldsymbol{\sigma}^{B}$ and $\dot{\boldsymbol{\sigma}}^{T}$ have their most compressive principal stress oriented $45^{\circ}$ with respect to the fault, as in "Rough" fault model \#1, there is little to no rotation of $\sigma_{H}$. Any misalignment between the open diamonds and black circles may be simply due to random processes such as the random sampling of the failure planes to create the seismicity or the statistical noise that is added to the failure orientations. When $\boldsymbol{\sigma}^{B}$ or $\dot{\boldsymbol{\sigma}}^{T}$ have their maximum compressive principal stress axis $\perp$ with respect to the major fault trend, as in model \#2 and model \#3, there is a greater rotation of $\sigma_{H}$ from stress inversions of the aftershock seismicity. Model \#2, which had a larger percentage of the aftershock seismicity in the stress shadow zone, especially experiences a rotation of $\sigma_{H}$.

In Fig. 10, the $\sigma_{H}$ rotations and changes of $\beta$ from stress inversions of aftershock seismicity are plotted for our three "Rough" fault models. The rotation of $\sigma_{H}$ for the subsection (solid line) can range from $<5^{\circ}$ for $\boldsymbol{\sigma}^{B}$ and $\dot{\boldsymbol{\sigma}}^{T}$ oriented $45^{\circ}$ with respect to the fault (model \#1) to almost $35^{\circ}$ when $\dot{\boldsymbol{\sigma}}^{T}$ has its maximum compressive principal stress direction $\perp$ to the fault (model \#2). Increases in the mean misfit angle, $\beta$, for the subsection (solid line) can range from $5^{\circ}$ to over $17^{\circ}$, depending on the relative orientations of the background stress, $\boldsymbol{\sigma}^{B}$, and the tectonic stressing rate, $\dot{\boldsymbol{\sigma}}^{T}$. Rotations of $\sigma_{H}$ and increases of $\beta$ are usually smaller and have shorter decay times when calculated for the entire upper $15 \mathrm{~km}$ of the model region as shown by the dashed lines in Fig. 10.

\section{Conclusions}

A version of DiETERICH (1994) rate-state formulation for seismicity rates is combined with models of 3-D spatially heterogeneous stress to create a modeling environment for studying aftershock sequences. We assume that faults in a region represent fixed sources of seismicity, oriented favorably with respect to the local stresses. A spatially uniform tectonic stressing rate, $\dot{\boldsymbol{\sigma}}^{T}$, and a 3-D static stress change, $\Delta \boldsymbol{\sigma}^{F}$, are resolved onto the right-lateral and left-lateral "potential" failure planes/slip directions at every grid point to define a reference Coulomb stressing rate, $\dot{S}_{r}$, and Coulomb stress change, $\Delta S^{F}$. The Coulomb stressing history, $\dot{S}_{r}$ and $\Delta S^{F}$, drives the seismicity rate as a function of time at each point through ratestate seismicity equations (Dieterich, 1994; DieteRICH et al., 2003). Each “potential” failure plane/slip direction, with its associated seismicity rate, is assumed to be a Poissonion source of seismicity with non-stationary rate; hence, there is some random probability that each "potential" failure plane/slip direction, with positive $\dot{S}_{r}$, will fail within a prescribed time and produce a synthetic focal mechanism for the catalog.

This model captures in a unified manner several aftershock features. For two of the three rough fault simulations, there is initial clustering of aftershocks in the Coulomb stress increase areas with a temporal migration back to a spatially uniform seismicity. Seismicity rates for all three models decay with approximately Omori law behavior. Aftershocks also occur in the traditionally Coulomb stress shadow regions. This occurs for two reasons: (1) The heterogeneous "potential" failure planes/slip directions, defined from the initial stress, engender a sufficient variation in resolved Coulomb stress for a few points to fail in the traditional Coulomb stress shadow zone. (2) Slip on geometrically complex faults produces small Coulomb stress increase asperities within the 

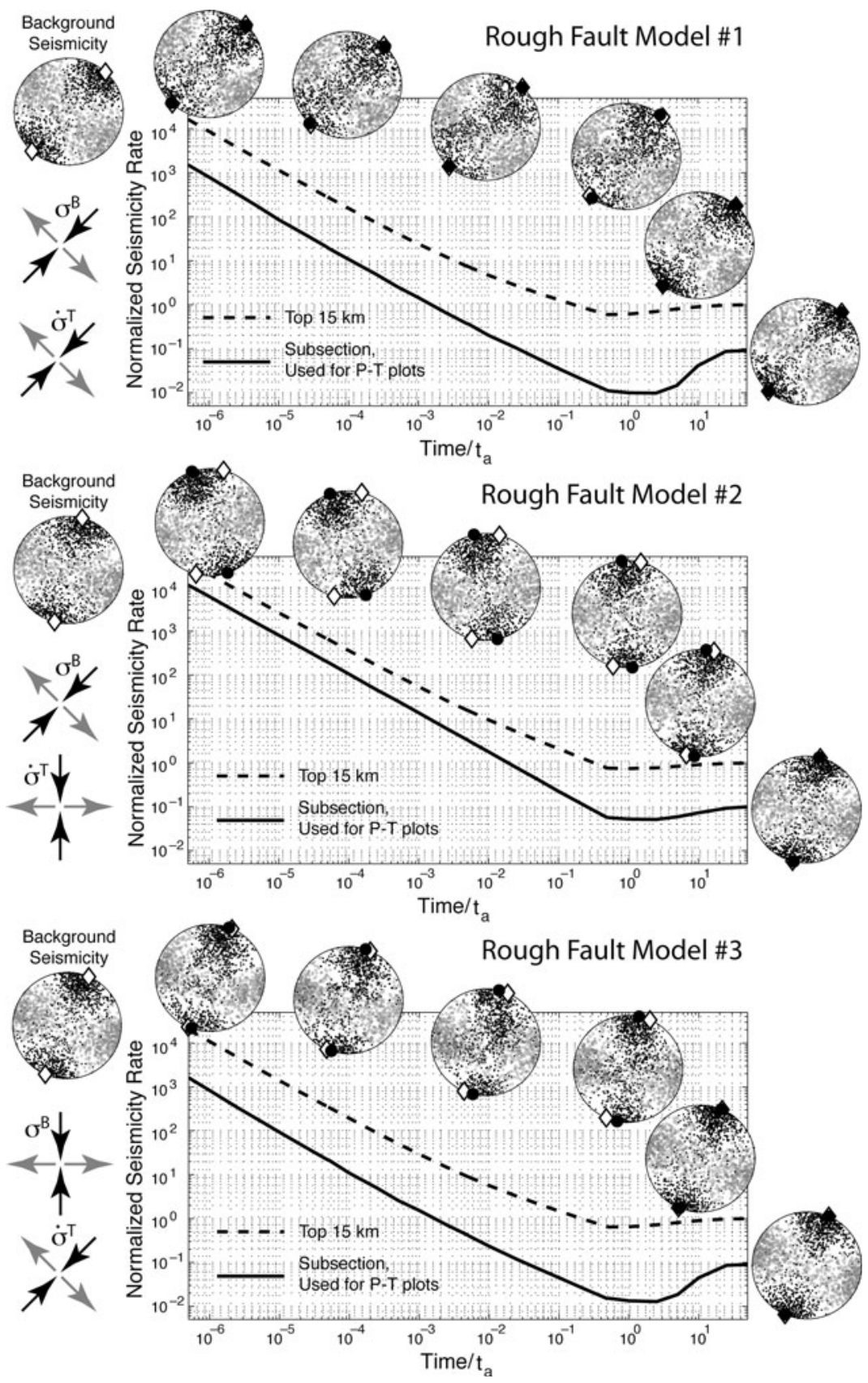

Figure 9

Plots of normalized seismicity rates, P-T axes, and inferred $\sigma_{H}$ orientations for aftershock seismicity. Note that the stereographic projections of $\dot{\boldsymbol{\sigma}}^{T}=0.02 \mathrm{MPa} /$ year and $\boldsymbol{\sigma}^{B}=50 \mathrm{MPa}$ are not to scale. In model $\# 1, \boldsymbol{\sigma}^{B}$ and $\dot{\boldsymbol{\sigma}}^{T}$ are both oriented at $45^{\circ}$ with respect to the overall fault trend. In model \#2, $\dot{\boldsymbol{\sigma}}^{T}$ has its maximum compressive axis $\perp$ to the fault trace, and in model \#3, $\boldsymbol{\sigma}^{B}$ has its maximum compressive axis $\perp$ to the fault trace. Dashed lines represent seismicity rates calculated for the entire upper $15 \mathrm{~km}$ of the model region, and solid lines represent seismicity rates calculated for the near fault subsection shown in Fig. 8. P-T plots show snapshots of focal mechanisms generated by aftershock seismicity in the subsection, and the angular difference between the open diamonds and the black circles shows the rotation of inferred $\sigma_{H}$ from stress inversions. Seismicity rates for both the subsection and entire model region for models \#1 through \#3 show Omori lawlike, $1 / t^{p}$ behavior with $p \approx 0.87$; however, the rate for the subsection overshoots its background rate then climbs back up at long times. The smallest rotation of inferred $\sigma_{H}$ occurs when $\sigma^{B}$ and $\dot{\sigma}^{T}$ are both oriented $45^{\circ}$ with respect to the fault in model \#1, and the largest inferred rotation occurs when $\dot{\boldsymbol{\sigma}}^{T}$ has its maximum compressive stress axis $\perp$ to the fault as in model \#2 

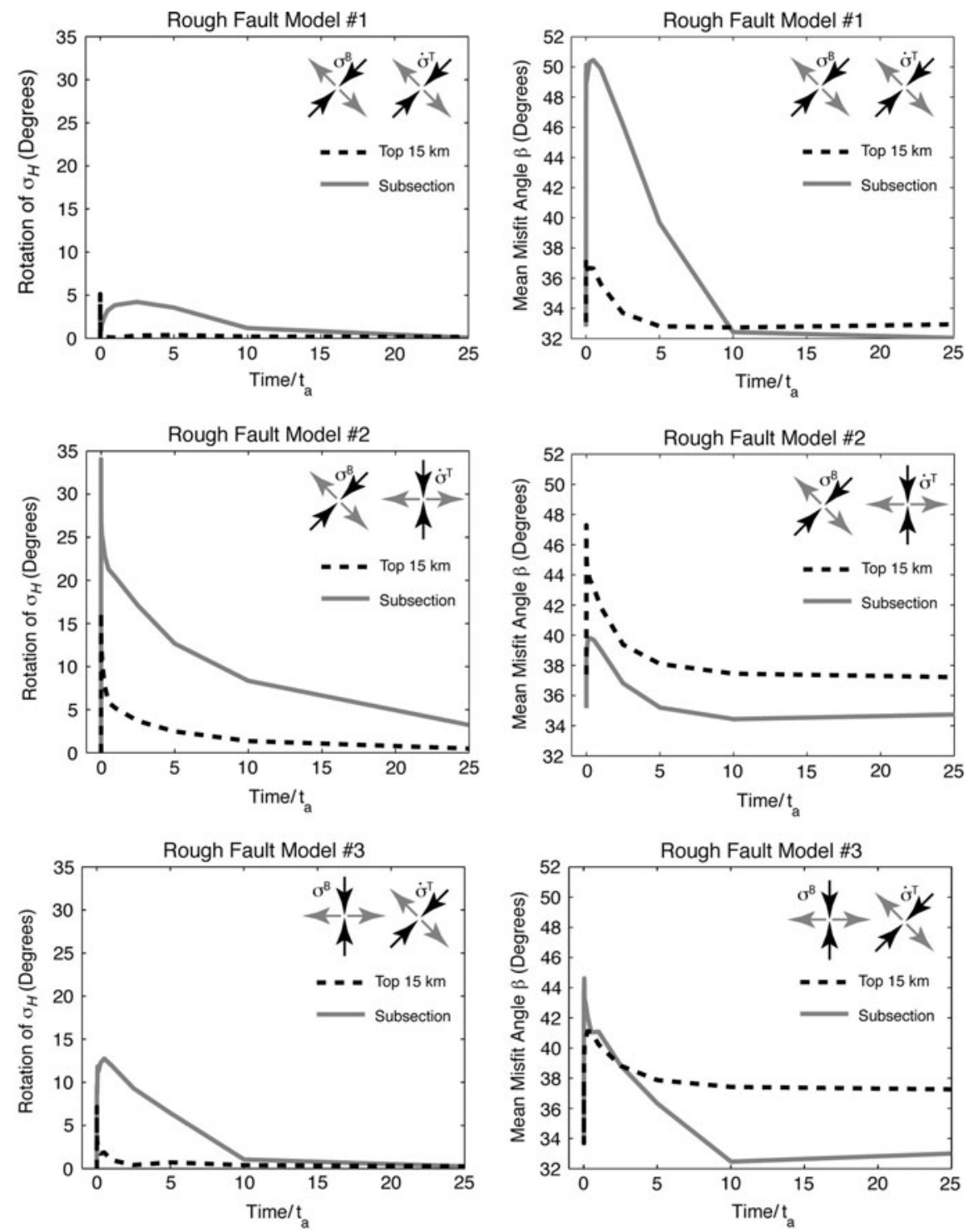

Figure 10

Rotations of inferred $\sigma_{H}$ on the left as a function of time and evolution of $\beta$ as a function of time on the right for the "Rough" fault models. Results are based on stress inversions of the synthetic aftershock focal mechanisms for different specified times. The solid lines represent seismicity from the subsection, and the dashed lines represent seismicity for the upper $15 \mathrm{~km}$ of the model region. Seismicity for the entire upper $15 \mathrm{~km}$ tends to have smaller changes in $\sigma_{H}$ and $\beta$ and much shorter decay times. Rotations of $\sigma_{H}$ can range from less than $5^{\circ}$ to almost $35^{\circ}$. Increases in $\beta$ can range from $5^{\circ}$ to over $17^{\circ}$ for the three scenarios shown

overall Coulomb stress shadow zone. These asperities occur close to and on the fault; hence, they concentrate aftershock seismicity along the fault trace. Both of these mechanisms may affect real aftershock sequences, and they may help explain why Coulomb static stress change analysis only partially correlates with aftershock seismicity.
This model also shows that synthetic focal mechanisms can produce large "apparent" rotations of the maximum horizontal compressive stress, $\sigma_{H}$, when a static stress change, $\Delta \boldsymbol{\sigma}^{F}$, is applied to a spatially heterogeneous stress field. For a $2 \mathrm{MPa}$ spatially uniform stress change, $\Delta \boldsymbol{\sigma}^{F}$, and an initial stress field, $\boldsymbol{\sigma}^{0}(\mathbf{x})$, with a $50 \mathrm{MPa}$ spatial mean and 
stress heterogeneity parameters $(\alpha=0.7, H R=2.5)$, the model can produce an "apparent" rotation of $\sigma_{H}$ anywhere from $4^{\circ}-33^{\circ}$, depending on the relative angle between $\Delta \boldsymbol{\sigma}^{F}$ and $\boldsymbol{\sigma}^{B}$. The expected "true" rotation of $\sigma_{H}$ from the summation, $\boldsymbol{\sigma}^{B}+\Delta \boldsymbol{\sigma}^{F}$, is less than $2^{\circ}$, much smaller than the "apparent" rotation of $\boldsymbol{\sigma}^{B}$ calculated from stress inversions of synthetic aftershocks. Models of uniform slip on geometrically complex faults can also produce significant "apparent" rotations of inferred $\sigma_{H}$ from inversions of synthetic aftershock focal mechanisms. At the same time, slip on these "rough" faults can create aftershock focal mechanisms that boost the stress inversion mean misfit angle parameter, $\beta$, anywhere from $5^{\circ}$ to over $17^{\circ}$, yielding an "apparent" increase in the stress heterogeneity. These effects, rotations of inferred $\sigma_{H}$ and increases in $\beta$, arise from the same highly nonlinear response of seismicity to a stress step that generates bursts of seismicity following stress perturbations that follow Omori's aftershock decay law. In a heterogeneous system with different fault plane orientations (reflecting heterogeneity of the initial stress), the nonlinear response of seismicity means that failure orientations favorably aligned toward the stress change will have a greater increase of seismicity than less favorably aligned orientations. Consequently, the seismicity following a stress change provides a sample of the fault planes and their associated slip directions, where the sample is biased in favor of failures aligned toward the optimal orientation for the stress perturbation.

These results indicate one cannot directly use rotations of $\sigma_{H}$ from stress inversions of aftershock seismicity to estimate the magnitude and orientations of stress in the Earth's crust. Additionally, these results indicate one must be careful when interpreting temporal changes in $\beta$ during aftershock sequences to study the time variation of stress heterogeneity. In our model of aftershocks, we can create a significant increase and subsequent decay of the mean misfit angle parameter, $\beta$, by updating as a function of time the ensemble of seismicity rates on temporally stationary failure orientations, rather than through "true" changes in stress; in other words, we can modify $\beta$ as a function of time through biasing effects alone. For several aftershock sequences, an increase in the parameter $\beta$ immediately after the mainshock has been observed, followed by a temporal decay (WoESSNER, 2005). While similar to our synthetic results, the aftershock data typically demonstrates $\beta$ variations with an amplitude at least double what we produce for the synthetic aftershock sequences in this paper. Undoubtedly, stress heterogeneity evolves due to the mainshock and during the aftershock sequence; hence, the safest conclusion is that changes in $\beta$ may need to be interpreted as a combination of both "true" changes in stress heterogeneity and biasing effects.

Understanding to what degree rotations of observed $\sigma_{H}$ from stress inversions are due to "apparent" versus "true" rotations could be important in resolving conflicting observations of crustal stress. Studies of aftershock seismicity have assumed that rotations of inferred $\sigma_{H}$ from aftershock stress inversions reflect a "true" rotation of the spatially homogeneous component of the total stress field and can be used to estimate the crustal stress (HARDEBECK, 2001; Hardebeck and Hauksson, 2000, 2001; HauKSSON, 1994; Provost and Houston, 2003; RATchKovski, 2003; WoesSNER, 2005); therefore, if the static stress change due to the main shock is relatively small and changes in inferred $\sigma_{H}$ are "true" rotations, then a low average crustal stress over the region, sometimes $<10 \mathrm{MPa}$, is necessary. Yet, other measurements of crustal strength, such as borehole breakouts, can estimate considerably larger crustal stress of the order $\geq 80 \mathrm{MPa}$ (HickMAN and ZobAck, 2004; Townend and ZoBACK, 2000, 2004; ZoBACK and Townend, 2001; ZоBACK et al., 1993).

In this paper, we demonstrate one potential solution to the reported crustal stress discrepancy by examining "apparent" rotations of $\sigma_{H}$ that naturally arise from stress inversions in a spatially heterogeneous stress field. Our simulations show that significant "apparent" rotations of inferred $\sigma_{H}$ can be created using moderate crustal strengths of $50 \mathrm{MPa}$; hence, one cannot definitively conclude weak crustal strengths of $<10 \mathrm{MPa}$ from rotations of $\sigma_{H}$, where $\sigma_{H}$ is inferred from stress inversions of aftershock seismicity.

\section{Acknowledgments}

This research was supported by the Southern California Earthquake Center. SCEC is funded by NSF 
Cooperative Agreement EAR-0106924 and USGS Cooperative Agreement 02HQAG0008. The SCEC contribution number for this paper is 1301. This material is based upon work supported by the National Science Foundation under Grant No. EAR0636064. Deborah would also like to thank her former graduate advisor, Thomas Heaton, for his encouragement and for their discussions at the California Institute of Technology, which led to her extrapolating the idea of biasing in a spatially heterogeneous stress field to aftershock sequences.

Open Access This article is distributed under the terms of the Creative Commons Attribution Noncommercial License which permits any noncommercial use, distribution, and reproduction in any medium, provided the original author(s) and source are credited.

\section{REFERENCES}

Andrews, D. J. (1980), A stochastic fault model: 1) Static case, J. Geophys. Res., 85, 3867-3877.

Andrews, D. J. (1981), A stochastic fault model: 2) Time-dependent case, J. Geophys. Res., 86, 821-834.

Arnold, R. and Townend, J. (2007), A Bayesian approach to estimating tectonic stress from seismological data, Geophys. J. Int. doi:10.1111/j.1365-246X.2007.03485.X.

Barton, C. A. and ZoBACK, M. D. (1994), Stress perturbations associated with active faults penetrated by boreholes: Possible evidence for near-complete stress drop and a new technique for stress magnitude measurement, J. Geophys. Res. 99, 9373-9390.

Ben-Zion, Y. and Sammis, C. G. (2003), Characterization of fault zones, Pure Appl. Geophys. 160, 677-715.

Deng, J. and SyKes, L. R. (1997a), Evolution of the stress field in southern California and triggering of moderate-size earthquakes: A 200-year perspective, J. Geophys. Res. 102, 98599886.

Deng, J. and Sykes, L. R. (1997b), Stress evolution in southern California and triggering of moderate-, small-, and micro-sized earthquakes, J. Geophys. Res. 102, 24411-24435.

DiETERICH, J. H. (1992), Earthquake nucleation on faults with ratedependent and state-dependent strength, Tectonophysics 211, 115-134.

Dieterich, J. H. (1994), A constitutive law for rate of earthquake production and its application to earthquake clustering, J. Geophys. Res.-Solid Earth 99, 2601-2618.

Dieterich, J. H. (ed.), Applications of Rate- and State-Dependent Friction to Models of Fault Slip and Earthquake Occurrence, 107-129 pp. (Elsevier B. V. 2007).

Dieterich, J. H. et al. (2003), Stress changes before and during the Puu Oo-Kupaianaha eruption. In: The Puи Oo-Kupaianaha Eruption of Kilauea Volcano, Hawaii: The First 20 Years, U.S. Geolog. Survey Prof. Paper, 1676, 187-202.

Dieterich, J. H. and SMith, D. E. (2009), Non-planar faults: Mechanics of slip and off-fault damage, Pure Appl. Geophys. 166, 1799-1815.
Elbanna, A. E. and Heaton, T. H. (2010, in preparation), Scale dependence of strength in systems with strong velocity weakening friction failing at multiple length scales.

Hardebeck, J. L. (2001), The crustal stress field in Southern California and its implications for fault mechanics, 148 pp., California Institute of Technology, Pasadena, California.

HARDEBECK, J. L. (2006), Homogeneity of small-scale earthquake faulting, stress and fault strength, Bull. Seismol. Soc. Am. 96, 1675-1688.

HardeBECK, J. L. and Hauksson, E. (2000), The San Andreas Fault in Southern California: A weak fault in a weak crust, 3rd Conf. Tectonic Problems of the San Andreas Fault System, Stanford, CA.

Hardebeck, J. L. and Hauksson, E. (2001), Crustal stress field in southern California and its implications for fault mechanics, J. Geophys. Res.-Solid Earth 106, 21859-21882.

HARDEBECK, J. L. et al. (1998), The static stress change triggering model: Constraints from two southern California aftershock sequences, J. Geophys. Res. 103, 24427-24437.

Hardebeck, J. L. and Shearer, P. M. (2003), Using S/P amplitude ratios to constrain the focal mechanisms of small earthquakes, Bull. Seismol. Soc. Am. 93, 2434-2444.

Harris, R. A. and Simpson, R. W. (1996), In the shadow of 1857the effect of the great Ft. Tejon earthquake on subsequent earthquakes in southern California, Geophys. Res. Lett. 23, 229-232.

HARRIS, R. A. et al. (1995), Influence of static stress changes on earthquake locations in southern California, Nature 375, 221224.

Hauksson, E. (1994), State of stress from focal mechanisms before and after the 1992 Landers earthquake sequence, Bull. Seismol. Soc. Am. 84, 917-934.

Helmstetter, A. and Shaw, B. E. (2006), Relation between stress heterogeneity and aftershock rate in the rate-and-state model, J. Geophys. Res. 111.

Helmstetter, A. and Shaw, B. E. (2009), Afterslip and aftershocks in the rate-and-state friction law, J. Geophys. Res. 114.

Herrero, A. and Bernard, P. (1994), A kinematic self-similar rupture process for earthquakes, Bull. Seismol. Soc. Am. 84, 1216-1228.

Hickman, S. and Zоваск, M. (2004), Stress orientations and magnitudes in the SAFOD pilot hole, Geophys. Res. Lett. 31, doi: 10.1029/2004GL020043.

KING, G. C. P. et al. (1994), Static stress changes and triggering of earthquakes, Bull. Seismol. Soc. Am. 84, 935-953.

LavalleE, D. and Archuleta, R. J. (2003), Stochastic modeling of slip spatial complexities of the 1979 Imperial Valley, California, earthquake, Geophys. Res. Lett. 30, Art. No. 1245.

Lund, B. and Townend, J. (2007), Calculating horizontal stress orientations with full or partial knowledge of the tectonic stress tensor, Geophys. J. Int. doi:10.1111/j.1365-246X.2007.03468.x.

MAI, P. M. and BerozA, G. C. (2002), A spatial random field model to characterize complexity in earthquake slip, J. Geophys. Res.Solid Earth 107, Art. No. 2308.

MANIGHETTI, I. et al. (2005), Evidence for self-similar, triangular slip distributions on earthquakes: Implications for earthquake and fault mechanics, J. Geophys. Res.-Solid Earth, 110, Art. No. B05302.

MANighetTI, I. et al. (2001), Slip accumulation and lateral propagation of active normal faults in Afar, J. Geophys. Res. 106, 13667-13696. 
McGill, S. F. and Rubin, C. M. (1999), Surficial slip distribution on the central Emerson fault during the June 28, 1992 Landers earthquake, California, J. Geophys. Res.-Solid Earth 104, 48114833.

Michael, A. J. (1984), Determination of stress from slip data: Faults and folds, J. Geophys. Res.-Solid Earth 89, 11517-11526.

Michael, A. J. (1987), Use of focal mechanisms to determine stress: A control study, J. Geophys. Res.-Solid Earth 92, 357368.

ОкаDA, Y. (1992), Internal deformation due to shear and tensile faults in a half-space, Bull. Seismol. Soc. Am. 82, 1018-1040.

OPPENHEIMER, D. H. et al. (1988), Fault plane solutions for the 1984 Morgan Hill, California earthquake sequence: Evidence for the state of stress on the Calaveras fault, J. Geophys. Res. 93, 90079026.

PollitZ, F. F. and SACKs, I. S. (2002), Stress triggering of the 1999 Hector Mine earthquake by transient deformation following the 1992 Landers earthquake, Bull. Seismol. Soc. Am. 92, 14871496.

Power, W. L. and Tullis, T. E. (1991), Euclidean and fractal models for the description of rock surface roughness, J. Geophys. Res. 96, 415-424.

Provost, A.-S. and Houston, H. (2003), Investigation of temporal variations in stress orientations before and after four major earthquakes in California, Phys. Earth Planet. Inter. 139, 255267.

Ratchкоvsкi, N. A. (2003), Change in stress directions along the central Denali fault, Alaska after the 2002 earthquake sequence, Geophys. Res. Lett. 30, 2017, doi:2010.1029/2003GL017905.

Reasenberg, P. A. and Simpson, R. W. (1992), Response of regional seismicity to the static stress change produced by the Loma Prieta earthquake, Science 255, 1687-1690.

Schaff, D. P. et al. (1998), Postseismic response of repeating aftershocks, Geophys. Res. Lett. 25, 4549-4552.

Scholz, C. H., The Mechanics of Earthquakes and Faulting, 2nd ed., 471 pp. (Cambridge University Press 2002).

Scholz, C. H. and Aviles, C. A. (eds.) (1986), The fractal geometry of faults and faulting, 147-156 pp., Am. Geophys. Union, Washington D.C.

Sмiтн, D. E. (2006), A new paradigm for interpreting stress inversions from focal mechanisms: How 3-D stress heterogeneity biases the inversions toward the stress rate, California Institute of Technology, Pasadena.

Smith, D. E. and Heaton, T. H. (2010), Simulations of 3D spatially heterogeneous stress-Potential biasing of stress orientation estimates derived from focal mechanism inversions, Bull. Seismol. Soc. Am., (submitted).
SteIn, R. S. (1999), The role of stress transfer in earthquake occurrence, Science 402, 605-609.

Stein, R. S. et al. (1997), Progressive failure on the North Anatolian fault since 1939 by earthquake stress triggering, Geophys. J. Int. 128, 594-604.

STEIN, R. S. et al. (1994), Stress triggering of the $1994 M=6.7$ Northridge, California, earthquake by its predecessors, Science 265, 1432-1435.

Toda, S. and SteIn, R. (2003), Toggling of seismicity by the 1997 Kagoshima earthquake couplet: A demonstration of timedependent stress transfer, J. Geophys. Res. 108, 2567.

TodA, S. et al. (1998), Stress transferred by the $1995 M-w=6.9$ Kobe, Japan, shock: Effect on aftershocks and future earthquake probabilities, J. Geophys. Res.-Solid Earth and Planets 103, 24543-24565.

Townend, J., What do faults feel? Observational constraints on the stresses acting on seismogenic faults. In Earthquakes: Radiated Energy and the Physics of Faulting, pp. 313-327 (American Geophysical Union 2006).

Townend, J. and Zoваск, M. (2000), How faulting keeps the crust strong, Geology 28, 399-402.

Townend, J. and ZовAск, M. D. (2001), Implications of earthquake focal mechanisms for the frictional strength of the San Andreas fault system. In The Nature and Tectonic Significance of Fault Zone Weakening, eds R. E. Holdsworth et al., pp. 13-21, Special Publication of the Geological Society of London.

Townend, J. and Zoваск, M. D. (2004), Regional tectonic stress near the San Andreas fault in central and southern California, Geophys. Res. Lett. 31, 1-5.

WaLsh, D. et al. (2008), A Bayesian approach to determining and parameterizing earthquake focal mechanisms, Geophys. J. Int. doi:10.1111/j.1365-246X.2008.03979.x.

Wilde, M. and Stock, J. (1997), Compression directions in southern California (from Santa Barbara to Los Angeles Basin) obtained from borehole breakouts, J. Geophys. Res. 102, 49694983.

Woessner, J. (2005), Correlating statistical properties of aftershock sequences to earthquake physics, Swiss Federal Institute of Technology, Zürich.

ZoBack, M. and TownEND, J. (2001), Implications of hydrostatic pore pressures and high crustal strength for deformation of the intraplate lithosphere, Tectonophysics 336, 19-30.

Zоваск, M. D. et al. (1993), Upper-crustal strength inferred from stress measurements to $6 \mathrm{~km}$ depth in the KTB borehole, Nature 365, 633-635.

Zoback, M. D. and BerozA, G. C. (1993), Evidence for near-frictionless faulting in the 1989 (M 6.9) Loma Prieta, California, earthquake and its aftershocks, Geology 21, 181-185.

(Received August 21, 2008, revised May 21, 2009, accepted July 15, 2009, Published online March 23, 2010) 